\begin{abstract}
Cooper, Phillip Shawn. Modeling Fluid Flows and Heat Transfer in Industrial Processes Using GOTHIC Software. (Under the direction of Dr. James W. Leach.)

Energy conservation measures in manufacturing plants and commercial facilities often involve modifications to convective processes. Examples of equipment used to carry out these processes include heating, ventilating, and air-conditioning equipment, refrigeration equipment, dust collection systems, drying and curing ovens, kilns, and melting cupolas. Because requirements and operating conditions change over time, there is often a need to modify existing equipment. The potential for energy savings may be very large, but engineers and plant managers are still reluctant to take action because it is not easy to predict the overall effects of proposed changes in such complex systems.

This work documents a case study to demonstrate how GOTHIC may be employed to improve a typical industrial process. GOTHIC is a general purpose thermal-hydraulics computer program originally developed for design, licensing, safety and operating analyses of nuclear power plant containments and other confinement buildings. It is a state-of-the-art program that solves conservation equations for mass, momentum, and energy for multi-component, multi-phase flows. The phase balance equations are coupled by mechanistic models for interface mass, energy and momentum transfer that cover the entire flow regime from bubbly flow to film/drop flow, as well as single phase flows. The code is user-friendly, and is capable of modeling systems with many components.
\end{abstract}


The case study evaluates proposed changes to a forced convection system for cooling urethane foam logs. The logs, which are about $30 \mathrm{ft}^{2}$ in cross section by $200 \mathrm{ft}$ in length, form when liquid chemicals react on an enclosed conveyor. The exothermic reaction continues for a few hours after the log is formed. Therefore, about $25 \operatorname{logs}$ are stored in racks at one time and cooled by refrigerated air. A ventilation system removes fumes from the storage area. The system is inefficient and costly to operate because the cooling airflow pattern is not optimized, and because cool air is removed by ventilation system. The GOTHIC code makes it possible to easily and quickly predict flows and air temperatures in the complex geometry, transient temperatures within the logs, and to optimize the cooling system. Model predictions are compared to experimental data. 


\section{Modeling Fluid Flows and Heat Transfer in Industrial Processes \\ Using GOTHIC Software}

by

\section{Phillip Shawn Cooper}

A thesis submitted to the Graduate Faculty of

North Carolina State University

in partial fulfillment of the requirements for the Degree of

Master of Science

\section{Department of Mechanical and Aerospace Engineering}

Raleigh, NC

August 2003

\section{APPROVED BY:}

Advisory Committee Member

Dr. Richard R. Johnson
Advisory Committee Member

Dr. Herbert M. Eckerlin

\section{Chair of Advisory Committee}

Dr. James W. Leach 


\section{BIOGRAPHY}

Phillip Shawn Cooper was born in Laurinburg, North Carolina on May 29, 1974. He is the son of Woodrow and Donna Cooper. He has two sisters and two brothers Leslie Cummings, Emily Cooper, Douglas Cooper, and Randall Cooper. He attended Hoke County High School where he participated in JROTC serving as a member of the Ranger and Rifle teams. He graduated high school in May 1992 and enrolled at DeVry Institute of Technology.

He received an Associate Degree in Electronics Engineering Technology and worked at Abbott Laboratories for three years. He married Beverly Shae Locklear in the summer of 1996. In the fall of 1999 Phillip enrolled in North Carolina State University and began work to receive a Bachelor of Science in Mechanical Engineering. He received this degree in December of 2001. Immediately following this degree, Phillip began taking graduate classes in the area of thermal science. Phillip began working under the direction of Dr. James W. Leach on modeling industrial processes using GOTHIC software. 


\section{ACKNOWLEDGEMENTS}

I would like to thank those persons at North Carolina State University and the professors in the Department of Mechanical and Aerospace Engineering for their answers to my many, many questions. I would like to thank Dr. James W. Leach, Dr. Richard R. Johnson, and Dr. Herbert M. Eckerlin for serving on my advisory committee. In particular I would like to thank Dr. Leach for giving me the opportunity to participate in such interesting work. I would like to thank Numerical Applications, INC. for allowing me to use their software for this work. I am indebted to Joe Sinodis for all his patience, knowledge and help with this research and all his invaluable information in response to my questions. Finally, I would like to thank my wife, parents, and family for their unconditional love and support throughout my educational career. I would also like to thank the many friends, who helped make this possible. 


\section{Table of Contents}

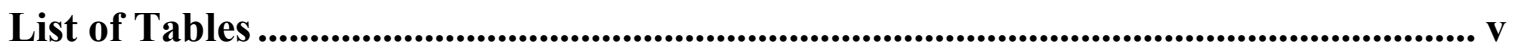

List of Figures................................................................................................................................... vi

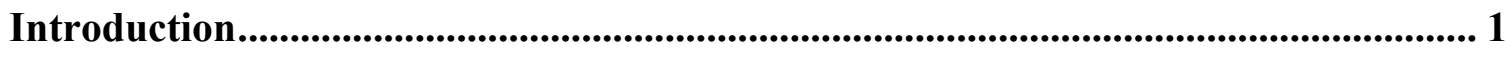

Facility Description ........................................................................................................... 3

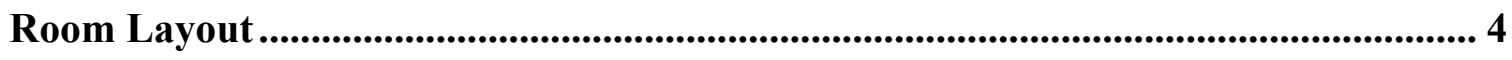

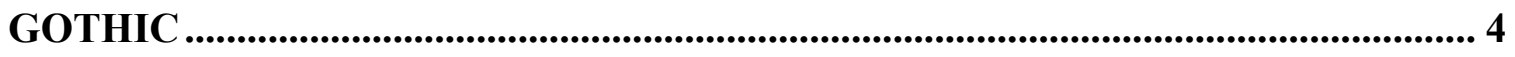

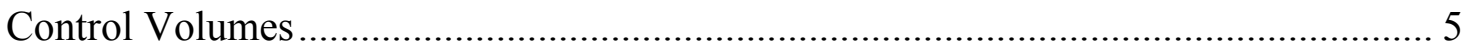

Boundary Conditions and Flow Paths................................................................... 10

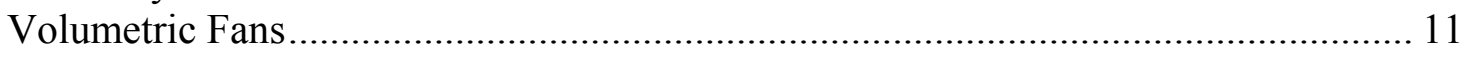

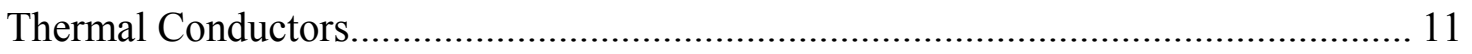

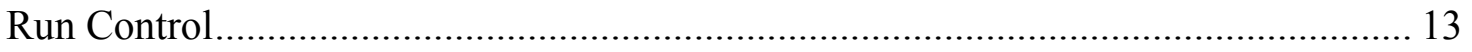

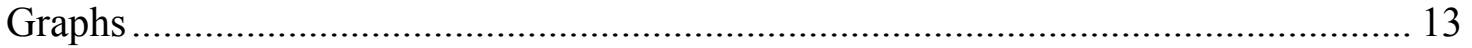

Modeling the Process ......................................................................................................... 14

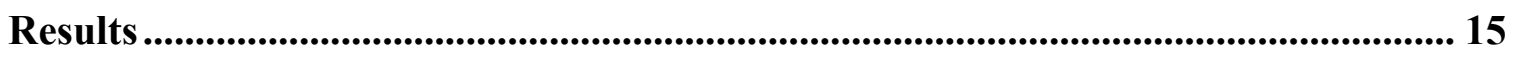

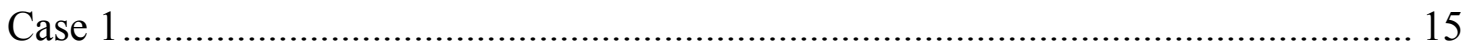

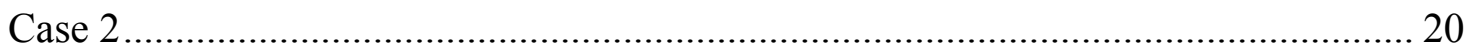

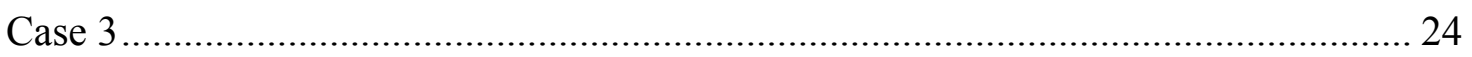

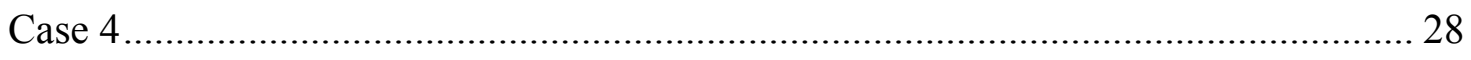

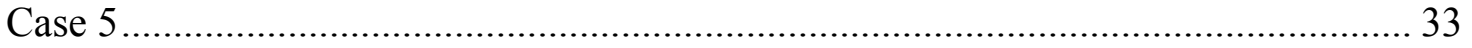

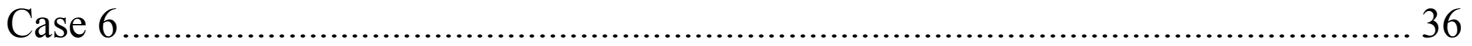

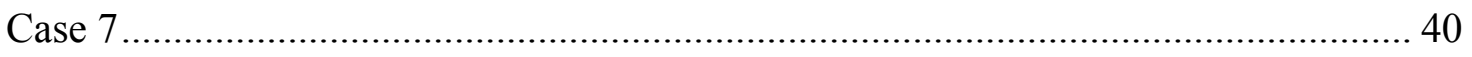

Recommendations ................................................................................................................... 43

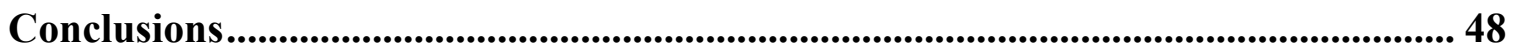

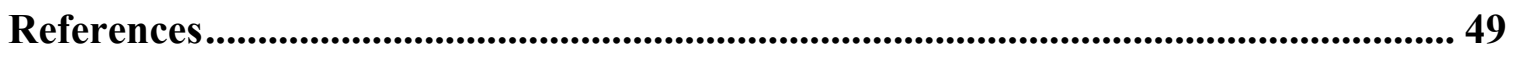




\section{List of Tables}

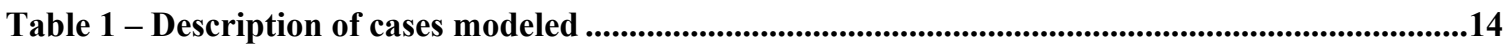

Table 2 - Results of cases modeled...............................................................................................47 


\section{List of Figures}

Figure 1- Isometric view of cooling room ........................................................................................................

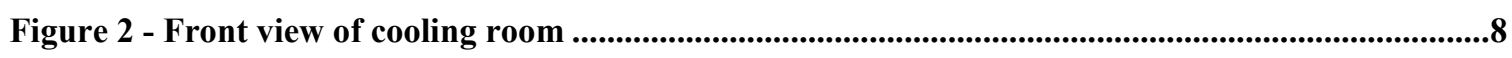

Figure 3 - Side view of cooling room .........................................................................................................................8

Figure 4 - Top view of cooling room .................................................................................................9

Figure 5. Noding diagram of the model......................................................................................................................12

Figure 6. \% Error during cooling ............................................................................................................16

Figure 7. Temperature of outer blocks at lower level for Case 1................................................................16

Figure 8. Temperature of inner blocks at lower level for Case1. ...................................................................17

Figure 9. Air velocities at lower level for Case 1..................................................................................................18

Figure 10. Temperature of inner blocks at mid level for Case1....................................................................19

Figure 11. Air velocities in mid level of room for Case 1. .......................................................................19

Figure 12. Air velocities at upper level for Case 1................................................................................................20

Figure 13. Temperature of outer blocks at lower level for Case 2 ..............................................................21

Figure 14. Temperature of inner blocks at lower level for Case 2. .......................................................22

Figure 15. Air velocities at lower level for Case 2 ..................................................................................22

Figure 16. Temperature of inner blocks at mid level for Case 2....................................................................23

Figure 17. Air velocities at mid level for Case 2 ................................................................................................23

Figure 18. Air velocities upper level for Case 2. ...................................................................................................24

Figure 19. Temperature of outer block at lower level for Case 3.................................................................25

Figure 20. Temperature inner block at lower level for Case 3....................................................................25

Figure 21. Air velocities at lower level for Case 3............................................................................................26

Figure 22. Air velocities at mid level for Case 3...........................................................................................27

Figure 23. Air velocities at upper level for Case 3...........................................................................................28

Figure 24. Temperature of outer block at lower level for Case 4.................................................................29

Figure 25. Temperature of inner block at lower level for Case 4..................................................................30 


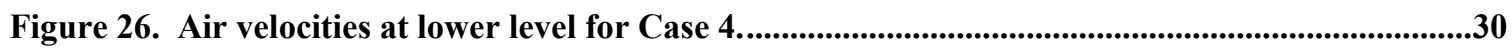

Figure 27. Temperature of inner block at mid level for Case 4.......................................................................31

Figure 28. Air velocities in mid level of room. ............................................................................................32

Figure 29. Air velocities in upper level of room..................................................................................................32

Figure 30. Temperature of outer block at lower level for Case 5........................................................33

Figure 31. Temperature of inner block at lower level for Case 4..................................................................34

Figure 32. Air velocities at lower level Case 5.....................................................................................34

Figure 33. Temperature of inner block at mid level for Case 5...................................................................35

Figure 34. Air velocities in mid level Case 5...........................................................................................35

Figure 35. Air velocities at upper level Case 5..................................................................................................36

Figure 36. Temperature of outer block at lower level Case 6.....................................................................37

Figure 37. Temperature of inner block at lower level Case 6............................................................................37

Figure 38. Air velocities at lower level Case 6.....................................................................................38

Figure 39. Temperature of inner block at mid level Case 6............................................................................39

Figure 40. Air velocities at mid level Case 6.......................................................................................................39

Figure 41. Air velocities at upper level Case 6.................................................................................................40

Figure 42. Temperature of outer block at lower level Case 7..........................................................................41

Figure 43. Temperature of inner block at lower level Case 7..........................................................................41

Figure 44. Air velocities at lower level Case 7................................................................................................42

Figure 45. Temperature of inner block at mid level Case 7...................................................................42

Figure 46. Air velocities at mid level Case 7.......................................................................................................43

Figure 47. Air velocities at upper level Case 7. .............................................................................................43 


\section{Introduction}

The work described in this report started with a case study done by the Industrial Assessment Center (IAC) at North Carolina State University. Members of the IAC visit many different manufacturing facilities to help determine energy and operational savings opportunities. Typically the IAC team will visit a plant and spend one day measuring temperatures, airflow rates, HVAC inlet and exit locations, door entrances, etc. so that a comprehensive case study can be done. Other data such as operational practices, energy requirements, and other production cost are requested from the plant engineers. In the weeks following the site visit each team member will analyze potential cost reducing measures. Each member will be responsible for evaluating a particular cost reducing item. The entire group will then meet to discuss the savings measures each member proposes. Simple payback periods for implementation of these changes are calculated. A report is then compiled and sent the plant suggesting ways to cut operational and energy cost.

When energy conservation measures are implemented at a manufacturing facility, it is often a long, difficult process. From the time a plant visit is made until energy savings are realized may take many months. A major shortcoming of this type of evaluation is to predict the actual overall effect the proposed changes will have. The consequences of changes to equipment that affect heat transfer are especially hard to forecast. In some cases the potential for energy savings may be very large but plant managers and engineers are reluctant to take action. A well tested computer code that is adaptable to a 
wide variety of systems is needed to predict the effects of changes in complex systems, and to convince plant engineers that proposed energy conservation measures can be implemented with minimal risks.

In the present work we investigate the feasibility of using the GOTHIC computer code in IAC case studies. GOTHIC, which has been under development for more than 20 years, is used extensively in the Nuclear Power Industry to study the effects of various types of containment issues. It is user friendly and is capable of analyzing complex systems. As a list case, proposed changes to a forced convection system for cooling urethane logs will be analyzed. Twenty-four logs are stored in racks at one time and cooled by refrigerated air. A ventilation system removes fumes from the storage are. This system is inefficient because conditioned air is removed from the room by the ventilation system, and because the airflow pattern is not optimized. Using the GOTHIC, flow patterns and air temperatures will be predicted, thus allowing the system to be optimized. Various proposed system changes will be modeled. Model predictions will be compared to existing data to determine the most efficient cooling scheme. 


\section{Facility Description}

The plant manufactures Polyurethane foam for use in automobile headliners and the textile industry. About 200 employees work three 8-hour shifts to operate the plant. The facility consists of two large buildings that contain production, warehouse, and office spaces. The building construction is concrete floors, walls and ceilings. Most of the facility is one level, however there are a few sub-levels located throughout the facility.

The process of making the headliner sheets is contained in-house. Liquid chemicals are poured onto a conveyor belt at one end. The reacting mixture travels down a conveyor, which is about 45 feet long. As the liquid travels it undergoes an exothermic reaction and expands as it changes to a solid state. The conveyor has a cover that constrains the expansion of the foam. The cross section of the cover has dimensions of 4 feet high by 8 feet wide. This process is continued until the foam block is 200 feet long. The foam block is then placed into a rack in an air conditioned cooling room where it is allowed to cool. When the blocks enter the cooling racks the exothermic reaction is almost completed and the temperature of the blocks is around $280^{\circ} \mathrm{F}\left(148.88^{\circ} \mathrm{C}\right)$. The blocks must be cooled to a safe temperature within a prescribed time to prevent damage.

Once the foam blocks are cooled to room temperature they are moved into another section of the plant for storage or use. As an approximation, it takes two shifts to process all of the foam that is poured on a single shift. Usually the foam is poured and cooled on the day shift and is cut on the afternoon and evening shifts. This means the foam blocks remain in the racks for approximately 8-12 hours. 


\section{Room Layout}

The cooling room is contained inside a secondary building that is offset from the main facility. The cooling area is 290 feet long, 54 feet wide, and 33 feet high. The layout of the room is physically symmetrical. The foam blocks are brought into the room by conveyor. The conveyor places the blocks on racks that are centered in the room from both the ends and sides. The cooling rack consists of 6 rows with 4 columns for a maximum of 24 spaces for storing the foam blocks. Conditioned air is used to cool the foam blocks while they are on the racks. Temperature and airflow measurements were taken at many different locations throughout the room during the site visit. Locations of HVAC ducts, exhaust fans, circulation fans, and doors were also identified.

\section{GOTHIC}

GOTHIC (Generation of Thermal-Hydraulic Information for Containments) is an advanced computer program used for solving complex fluid flow and heat transfer problems. It uses a flexible noding scheme to model single and multiphase flows with phase change. Numerous built-in components are included to conveniently model and control equipment typically found in ventilation and hydraulic systems. GOTHIC includes special features for modeling nuclear power plant containments, auxiliary buildings and plant equipment. It is one of the leading software packages used in the nuclear industry. However, its popularity is not evident outside the nuclear industry. GOTHIC solves equations for conservation of mass, momentum, and energy along with state equations to analyze highly complicated thermal-hydraulic problems involved with containment issues. These problems are not only found in the nuclear industry but also in 
manufacturing plants. For this reason it seems GOTHIC would be useful for solving thermal-hydraulic problems associated with manufacturing processes. Another helpful aspect of GOTHIC is that it is very user friendly. The present work will help determine whether it can be effectively used by IAC students to solve manufacturing problems. If this is true, it could reduce the amount of time it takes to compile a report and expand the types of recommendations that could be made after an audit is done. More audits could be compiled and more manufacturing plants would have the opportunity to reduce operational costs. Plant managers and engineers would be more willing to implement cost saving measures. GOTHIC 7.1 was used was to model the foam cooling process.

\section{Control Volumes}

A control volume is a required feature of every GOTHIC model. Other features of the model are assigned to the control volume. There are two types of volumes that may be chosen. A lumped volume is used to represent a space that has constant properties. Temperatures, flows, and other room properties are assumed to be an average. This means the ceiling and floor may actually be at two different temperatures, but by using a lumped volume the entire room will be modeled at one temperature. An advantage to using lumped volumes is the simplicity of the setup. Flow paths connect lumped volumes. Once the volume is drawn dimensions are assigned in either English or Metric units. Along with volume dimensions, the hydraulic diameter and fluid properties are entered via a mean interface in tabular format. 
A more accurate and versatile way of representing a room is by using a subdivided volume. A subdivided volume may be thought of as a space with non-uniform properties that is divided into "smaller" subvolumes. If a room has a dramatic temperature or fluid flow disparity, then subdivided volumes are more appropriate to use. An example would be a large room with a heater on one end. A volume may be divided into as many subdivisions as required or desired by the user. Each subvolume is allowed to have different dimensions. However, more detail is required when using subdivided volumes. Each subvolume must be assigned a hydraulic diameter and volume porosity. The hydraulic diameter and volume porosity may change for each subvolume depending on its shape and contents. When using subvolumes it is not necessary to create a flow path. Using subvolumes allows for very complicated flow within a room. GOTHIC solves conservation of mass equations and determines flow patterns. After the visit to the subject plant it was determined that a model consisting of a subdivided volume would be more appropriate than a lumped volumes connected by flow paths. This choice was due to complex airflows throughout the cooling room. There are large cooling fans on each end of the room and many registers along the length of the room for the HVAC system. With the large number of air moving devices, a lumped volume would not be very realistic. The cooling room was divided into a $10 \times 7$ X 6 mesh, which corresponds to 420 subdivided volumes. For each subvolume a hydraulic diameter must be calculated using the following equation.

$$
H_{D}=\frac{4 V}{A_{W}} \text { where; }
$$




$$
\begin{gathered}
\mathrm{V}=\text { volume of subvolume } \\
A_{W}=\text { wettable area }
\end{gathered}
$$

The wettable the area is area where condensation or water droplets could form in the subvolume. The symmetrical setup allows for corresponding volumes in each computational grid to have the same hydraulic diameter. With all properties of each subvolume determined and added to the model the setup of the subvolumes is complex. Figures 1-4 show the subdivided volumes used to model the cooling room. All dimensions are in feet.

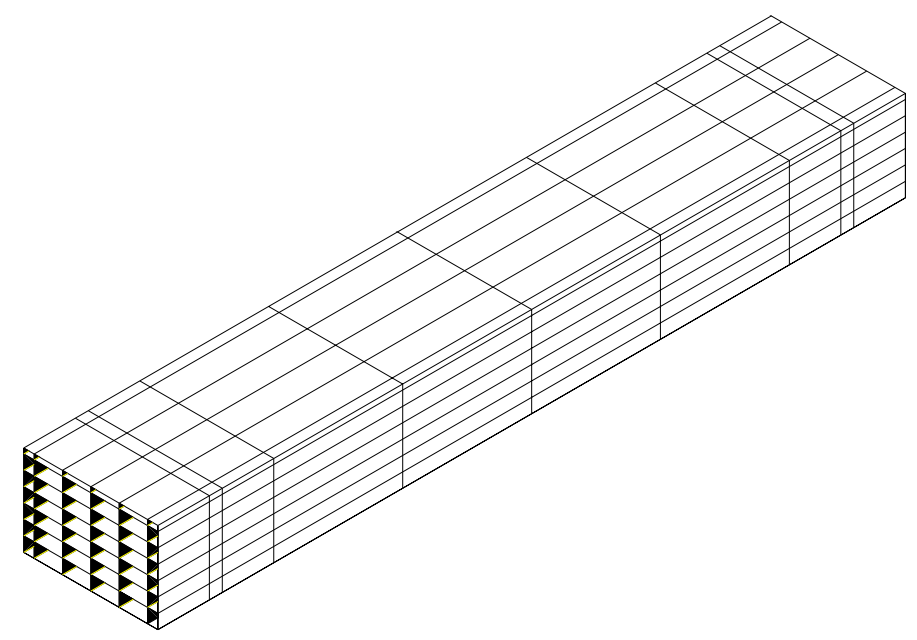

Figure 1- Isometric view of cooling room 


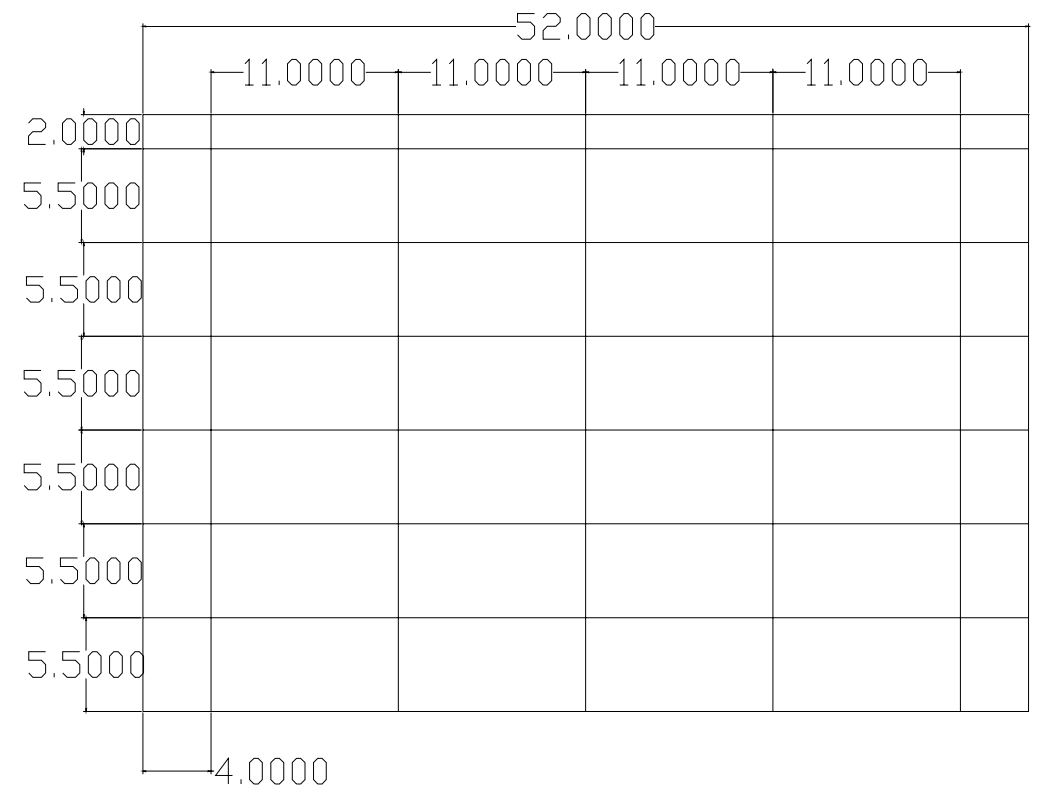

Figure 2 - Front view of cooling room

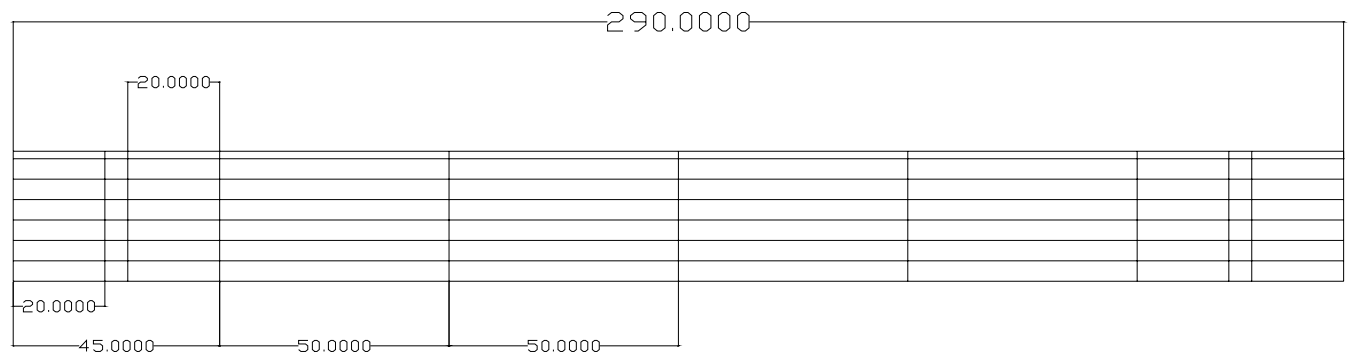

Figure 3 - Side view of cooling room 


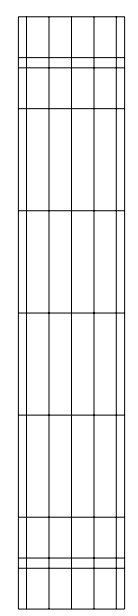

Figure 4 - Top view of cooling room 


\section{Boundary Conditions and Flow Paths}

The HVAC system for the cooling room has two main air ducts with 15 drops from each duct on each side of the room. Each drop has 6 registers, for a total of 180 outlets for the conditioned air. Each register had an airflow speed of $8.2 \mathrm{~m} / \mathrm{s}$, which corresponds to $49,200 \mathrm{ft}^{3} / \mathrm{min}$ for the entire room. The registers had a cross section of $8 \mathrm{in}$. by $10 \mathrm{in}$. a seventy percent multiplier was applied because the registers were not completely open. This approximation yielded a total incoming flow rate of $34,440 \mathrm{ft}^{3} / \mathrm{min}$. Eight boundary conditions with constant temperatures of $45^{\circ} \mathrm{F}$ that matched the measured temperature were used to model the HVAC system. The boundary conditions were connected to the room using flow paths. The flow paths are assigned elevations for each end. Elevations of the path ends determine if there is a pressure difference along the path. Flow area, hydraulic diameter, and inertia length must be given for each path. With this information the airflow can be modeled through the flow path. A relative roughness parameter may be assigned but for this case it will be assumed that the ducts are smooth. One end of the path was connected to the HVAC boundary condition and the other to a subdivided cell. The eight HVAC boundary conditions had a flow rate of $71.75 \mathrm{ft}^{3} / \mathrm{s}$ or $1 / 8$ of the total incoming air flow. Each path represents 3.75 duct drops in the cooling room. Another boundary condition was used to represent the atmospheric conditions. This boundary condition was setup with constant pressure and a temperature of $75^{\circ} \mathrm{F}$. An exhaust fan located in the cooling room extracts air from the cooling room through a flow path into the atmosphere. 


\section{Volumetric Fans}

There were also four fans used for circulation of conditioned air. At the entrance of the cooling room the two fans are attached to the ceiling forcing air toward the exit. Near the exit two fans sit on the floor forcing air toward the entrance. This setup attempts to create a circular motion flow. The fan blades have a 3 feet diameter. This allows for large mass flow rate. In the model volumetric fans create the fan flow. This allows for a volumetric flow rate to be assigned to the fans. The fans are placed inside a subdivided volume with positive orientation. The air is able to flow from fan to subvolume and subvolume to adjacent subvolumes without flow paths or network links. With control volumes, boundary conditions, volumetric fans, and flow paths added the model was run to get baseline results.

\section{Thermal Conductors}

Thermal Conductors are used to model heat capacity within solids, heat transfer between solids and fluids, heat transfer between solid surfaces and radiative heat transfer

among structures. A spanned thermal conductor may also be used. A spanned conductor may be used as an internal conductor for a subdivided volume. This allows for a thermal surface to be distributed to any one, two, or three-dimensional rectangular array of cells in a subdivided volume. A spanned thermal conductor represents each foam block in the cooling room. The conductor is spanned such that it is located in a row of subvolumes that correspond to the foam placement in the cooling room racks. Once the spanned conductor is added to the model it must be defined. The thermal properties of the 
material are defined. These properties along with the physical dimensions of the conductor are entered in tabular form. The conductor was modeled with wall geometry. The plate has two sides, each must have a mode of heat transfer assigned. Side A is modeled as the center of the block therefore no heat transfer takes place. Side B is modeled as the outer edge of the block and the default Direct Heat Transfer option is selected.

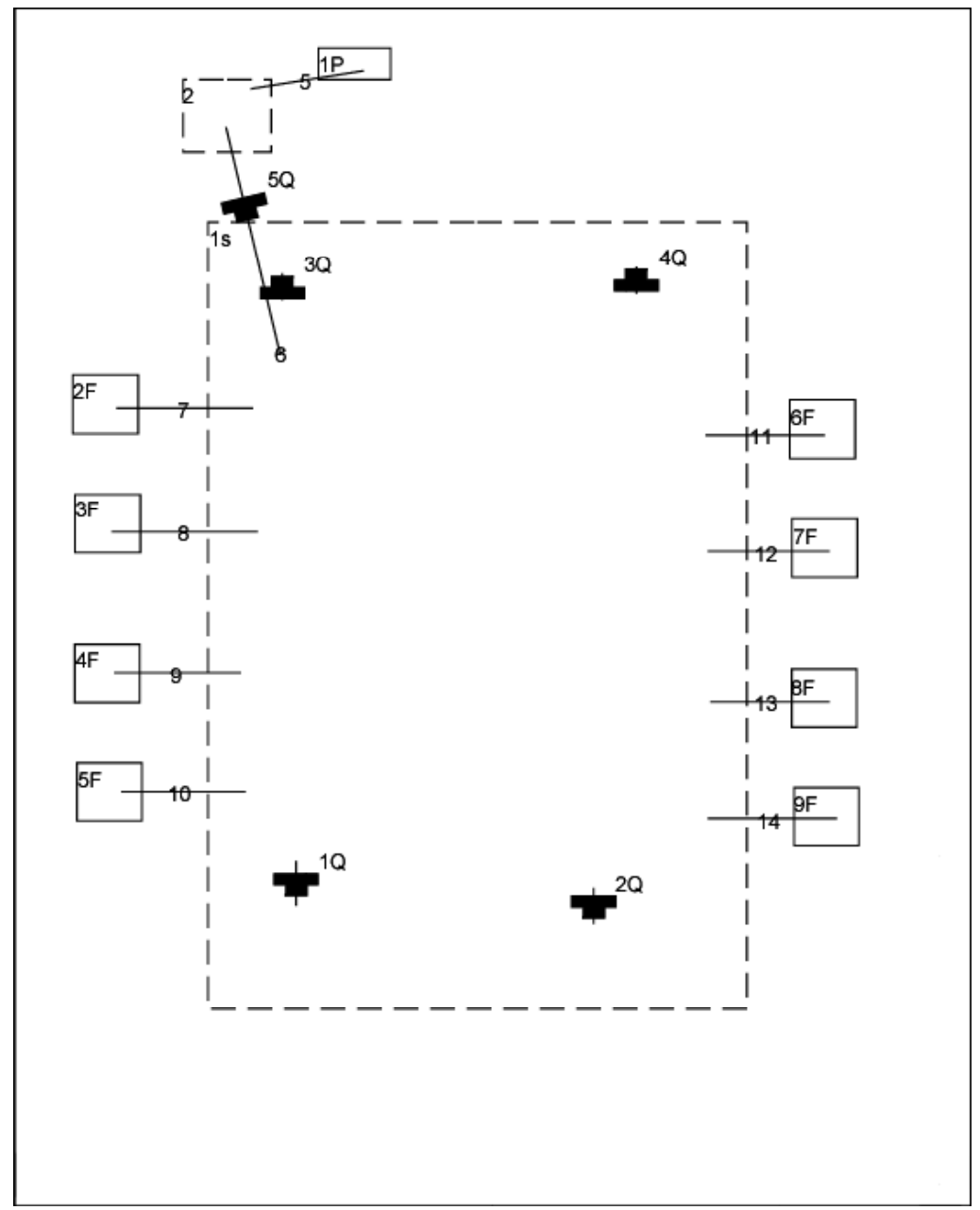

Figure 5. Noding diagram of the model 


\section{Run Control}

The run control allows the user to set time domains of a run. The time domain menu allows a user to edit the run parameters. A user is allow to set as many time domains as needed. The user may set minimum and maximum CPU time steps. The minimum time step puts a lower limit on the time step in the current time domain. The maximum time step puts an upper limit on the time step in the current time domain. The CPU may run at either time step but must remain with the limits. If the maximum is too large the results may be inaccurate and may produce oscillations in graphical data. Another important time is the transient time. This is the transient end time for the current domain. A user can also define a maximum CPU time for each domain; the simulation will be interrupted if the maximum CPU time is exceeded. Time domains can have different time settings than a preceding or proceeding time domain.

\section{Graphs}

GOTHIC has a graphic package that allows users to access results from a simulation and display the results on a line, contour, or vector graph. Line graphs are a dependent function verses time. The one exception is a temperature profile of a conductor at one point in time. Another graph is the contour graph. This graph is only used to show output in planes defined from subdivided volumes. Contour graphs are used to display temperature, pressure, or gas pressure ratio. Contour graphs may be defined from vertical or horizontal planes from any subdivide volume. 


\section{Modeling the Process}

With all parameters defined in GOTHIC the task was to run the model and get useful information. A model simulating the current cooling room conditions was used to get baseline results. The model was then modified to incorporate various energy conservation measures. The current cooling room set-up was modified to simulate other set-ups. The modifications of the model took about 15 minutes to incorporate. It took about 3 hours to simulate the 8 hour process. The goal is to optimize the cooling process. It is hoped that cooling may be accomplished in a more efficient manner. Minor modifications may be implemented at a present cost, but could save the facility energy and could reduce cooling time. Table 1 lists the cases that are considered below.

\begin{tabular}{|c|c|}
\hline Case 1 & Current cooling room set-up \\
\hline Case 2 & Circulation Fans Off \\
\hline Case 3 & HVAC Off \\
\hline Case 4 & Curtains Installed on Empty Racks \\
\hline Case 5 & Adding Fans with HVAC \\
\hline Case 6 & Adding Fans without HVAC \\
\hline Case 7 & Adding fans at Mid-Level of Room \\
\hline
\end{tabular}

Table 1 - Description of cases modeled 


\section{Results}

The results for each case are listed below. Once of the most important parameters is the centerline temperature of the foam blocks. The temperature of the foam must not rise above $330^{\circ} \mathrm{F}$, which is the ignition temperature. Also the inside temperature must be reduced at a relatively fast rate to keep the foam from becoming too soft. For this reason much attention will be focused on the inside temperature. For each case, all results will be compared from the same locations. For the plots of temperature vs. relative distance below, 0 corresponds to the center and 1 corresponds to the outside edge of the foam. The conduction model is two-dimensional. Temperature varies in the radial direction and in the axial direction.

\section{Case 1}

The objective of this run is to get results that can be used to evaluate proposed to changes in cooling process. This will be the baseline model from which all others will be evaluated. 


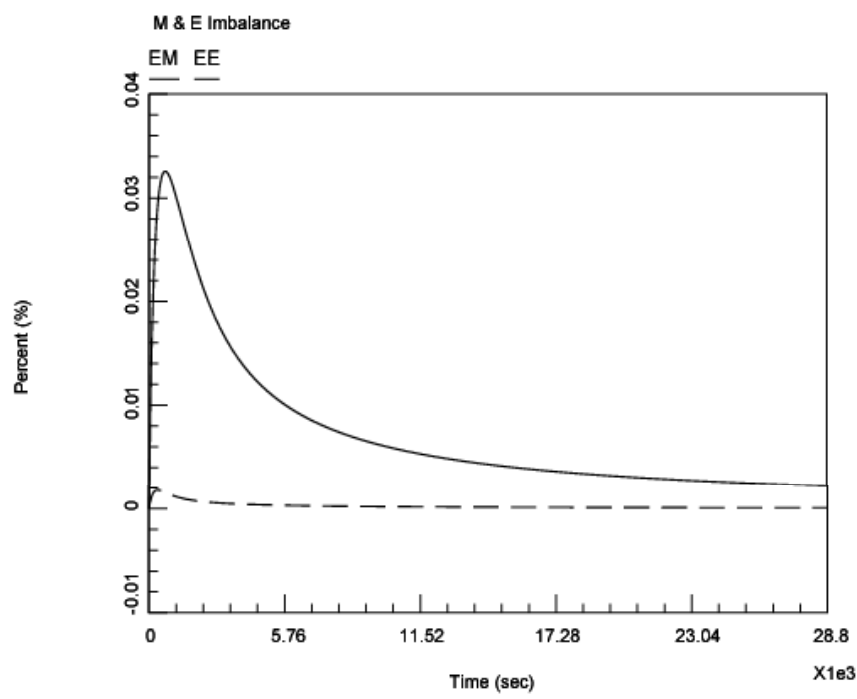

Figure 6. \% Error during cooling

Using conservation of energy and mass GOTHIC calculates the errors associated with the model. Figure 6 shows that the mass and energy error jumps slightly at the start of the run. After about 30 minutes the model stabilizes and both errors approach zero. This is acceptable.

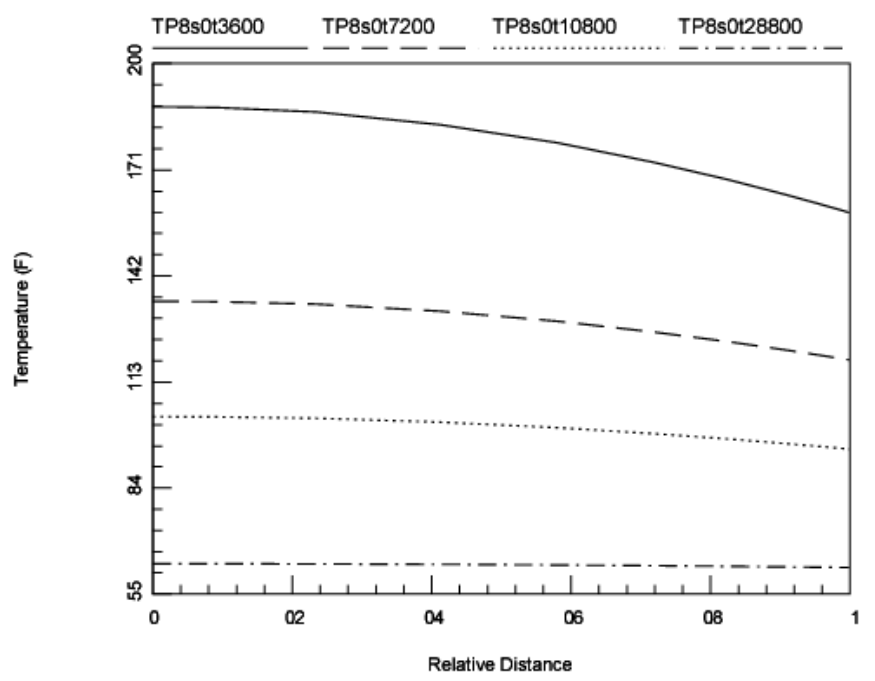

Figure 7. Temperature of outer blocks at lower level for Case 1.

Figure 7 shows that after 8 hours of cooling the inside and outside of the block is at uniform temperature of $63^{\circ} \mathrm{F}$. This is for blocks located on the outer portion of the 
stacking arrangement. Measurements taken during the visit found that the temperature of the blocks ranged from $62-69^{\circ} \mathrm{F}$. Measurements also showed that the inner blocks of the arrangement were at a slightly higher temperature than the outer blocks. These temperatures ranged from $69-77^{\circ} \mathrm{F}$. The figure below shows the same trends are present in the model. This figures shows that after 8 hours of cooling the inner blocks are cooled to $78^{\circ} \mathrm{F}$. For this the cooling of the blocks is not uniform throughout the arrangement. The blocks along outer edge cool at a faster rate than those in the inner part of the arrangement.

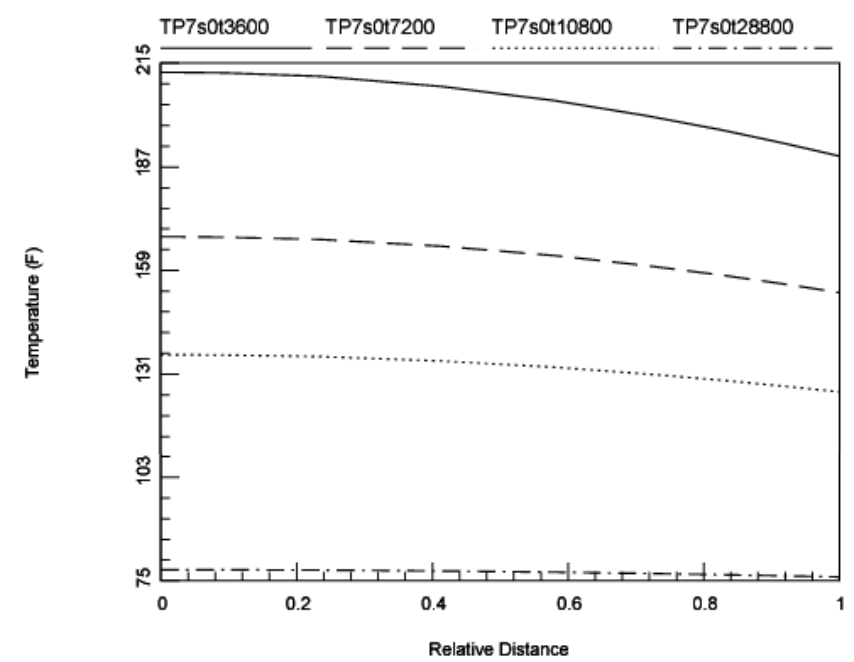

Figure 8. Temperature of inner blocks at lower level for Case1. 


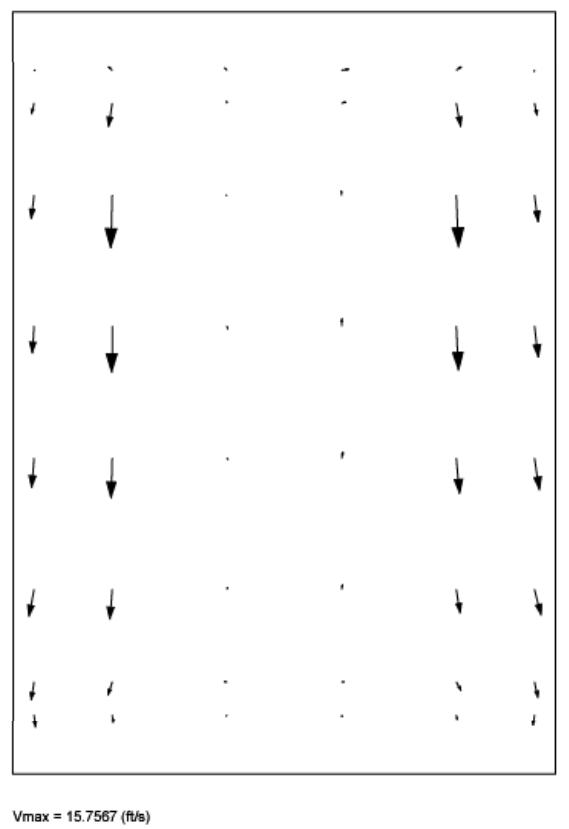

Figure 9. Air velocities at lower level for Case 1.

Figure 9 is a graph that shows the velocity vectors at various locations in the room. The vectors are taken from a plane in the lower level of the room. This shows the velocities looking from the top view. The velocity is higher near the circulation fans. It is important to note that the fans have little effect on velocities in cells away from the fans. 


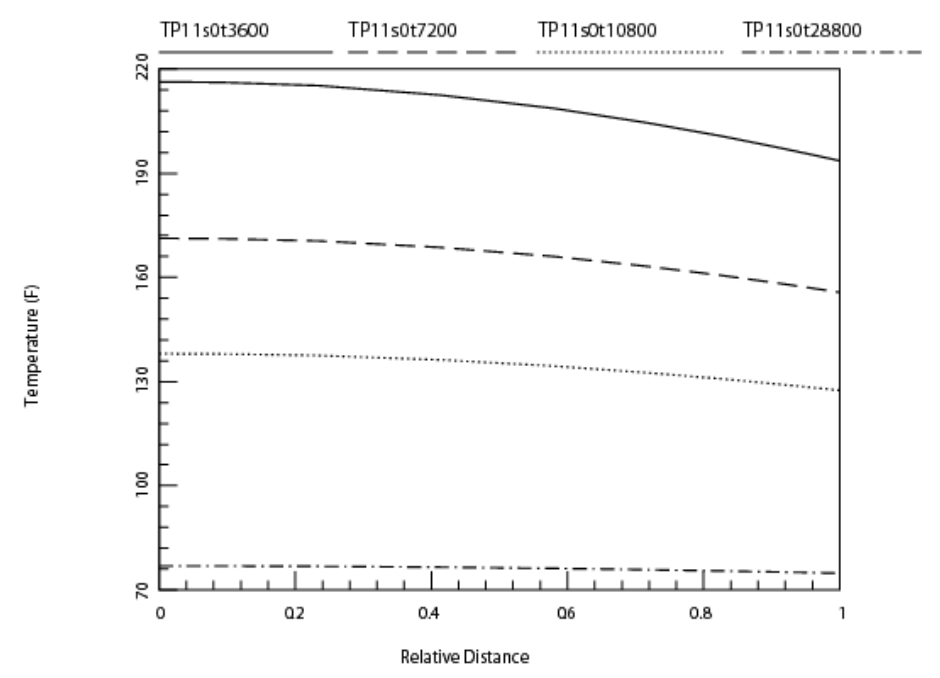

Figure 10. Temperature of inner blocks at mid level for Case1.

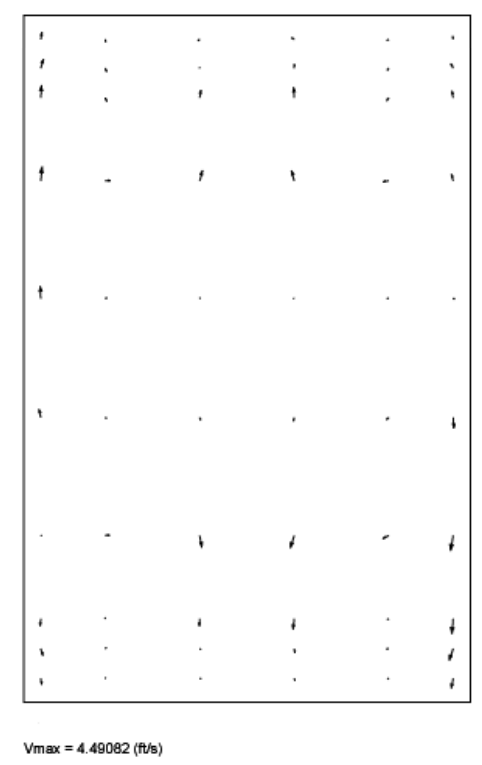

Figure 11. Air velocities in mid level of room for Case 1.

Figure 11 shows that the air velocity of the room at mid-height is considerably lower than at the lower level. The small velocity is a result of the circulation fans being attached to 
the floor and the ceiling. The lower air velocity causes the blocks at the mid level of the room to cool at a slower rate than those in the lower and upper levels.

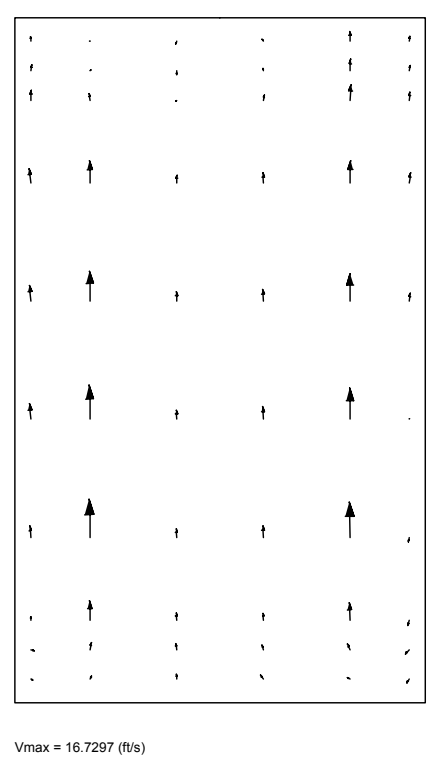

Figure 12. Air velocities at upper level for Case 1.

Figure 11 shows the air velocity in the upper level of the room. It is similar in magnitude to the lower level but in the opposite direction. From Case 1 it is important to note that the calculated results are very close to the measurements taken during the plant visit. This assures the model actually represents the process.

\section{Case 2}

From the base run it is evident that the circulation fans don't play a major role in some areas of the room. There are four fans, which have a combined power of about 60 horsepower. The objective of this run is to see if comparable cooling can be achieved without running the circulation fans. In this case air would still flow from the air 
condition ducts into the room, and would leave because of the action of the ventilation fan.

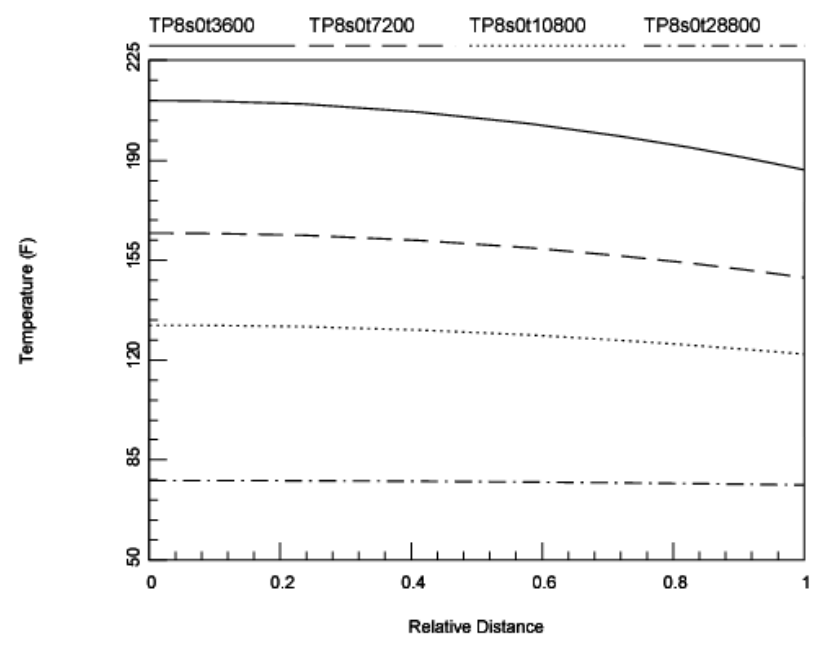

Figure 13. Temperature of outer blocks at lower level for Case 2 .

From figure 13 the outer block temperatures at the various times are higher than those in Case 1 (see Figure 7). However the blocks have reached a uniform temperature of $78^{\circ} \mathrm{F}$. The inner blocks have also reached a temperature of about $78^{\circ} \mathrm{F}$. For this case the temperature difference between the inner and outer blocks in smaller than Case 1. This also shows that all the blocks cool at nearly the same rate no matter where in the arrangement they are located. 


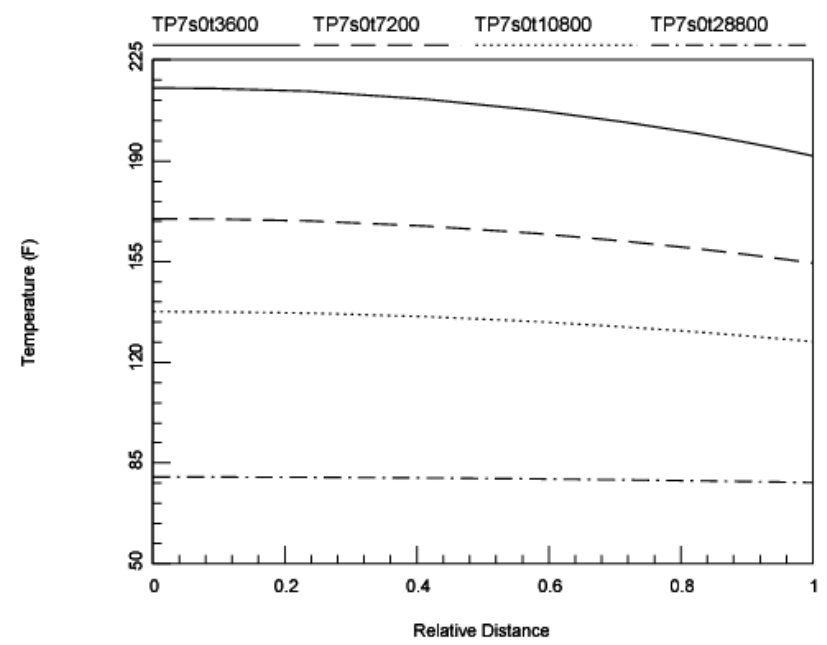

Figure 14. Temperature of inner blocks at lower level for Case 2.

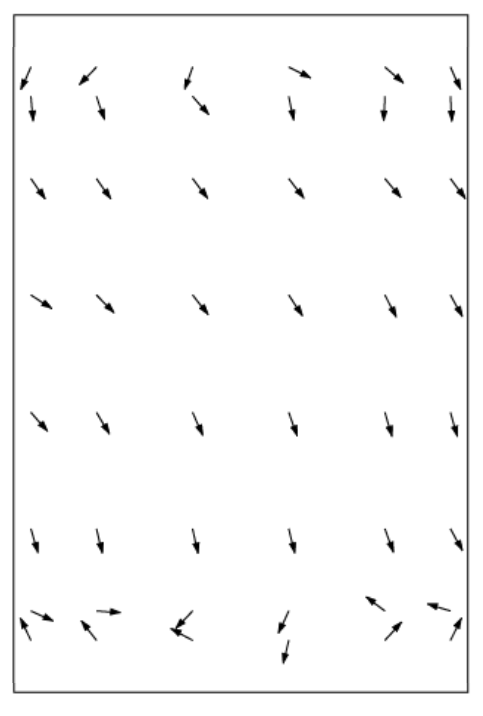

$V \max =15(\mathrm{f} / \mathrm{s})$

Figure 15. Air velocities at lower level for Case 2. 


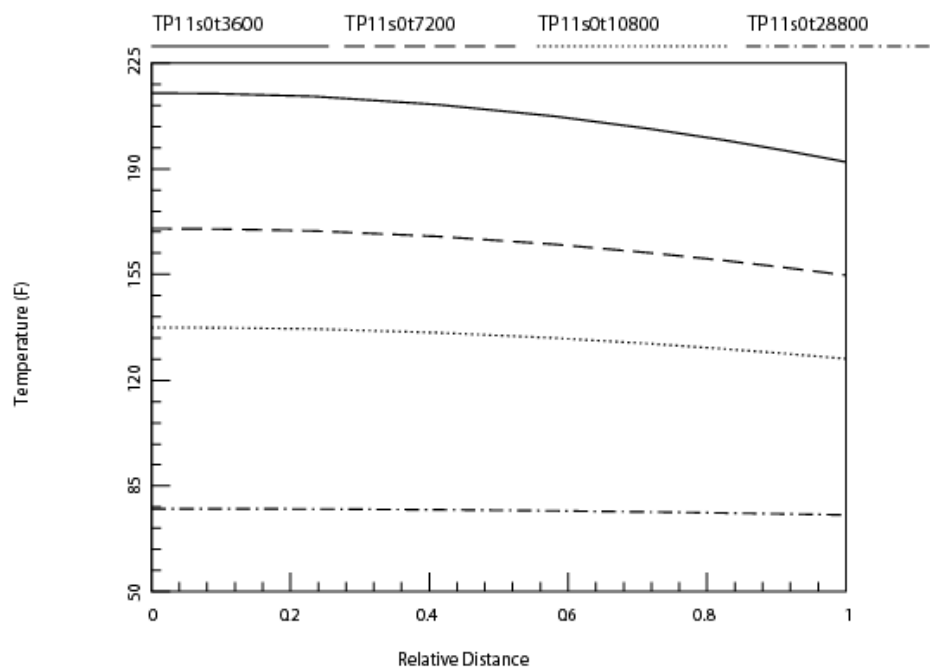

Figure 16. Temperature of inner blocks at mid level for Case 2.

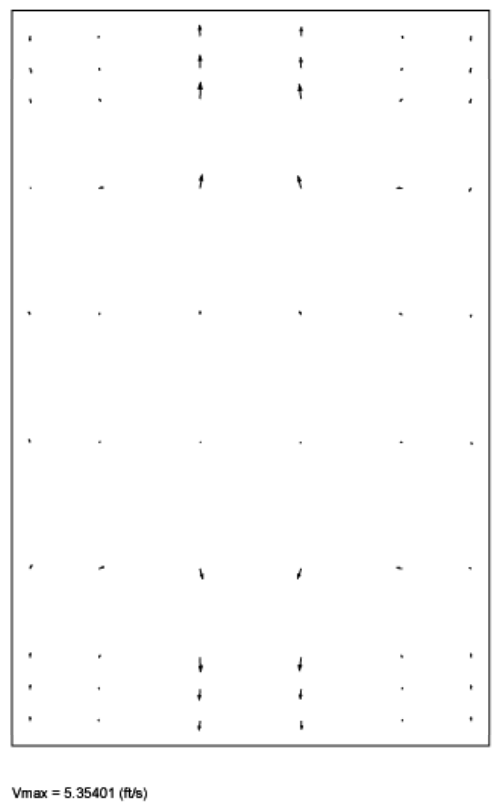

Figure 17. Air velocities at mid level for Case 2. 


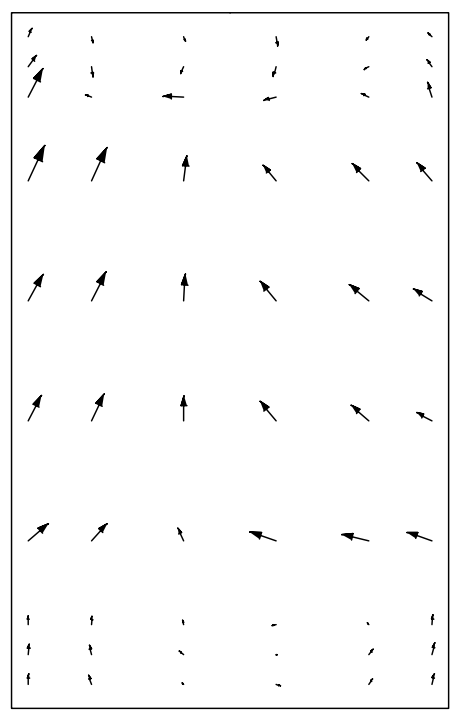

$V \max =2.07302(\mathrm{ft} / \mathrm{s})$

Figure 18. Air velocities upper level for Case 2.

The velocities shown figure 15-18 are more uniform than those for case 1. This explains why case 2 has such uniform cooling over the entire arrangement of blocks. The velocities in the room are more uniform thus creating similar conditions for heat transfer to take place. That is not the situation in case 1 . The fans caused more flow along the outer portion of the arrangement thus allowing those blocks to cool faster. Case 2 presents a more predictable scenario. This allows for more accuracy in determining the time it takes to cool the blocks.

\section{Case 3}

The current process uses a HVAC system to cool the blocks. The ventilation fans exhaust the conditioned air. This process is not energy efficient because the conditioned air is not circulated and used again. Case 3 determines the cooling pattern when the 
HVAC system is not used. Atmospheric air at $90{ }^{\circ} \mathrm{F}$ enters the room through the air conditioning ducts. The objective of this run is to evaluate the cooling process with 4 circulation fans and no conditioned air.

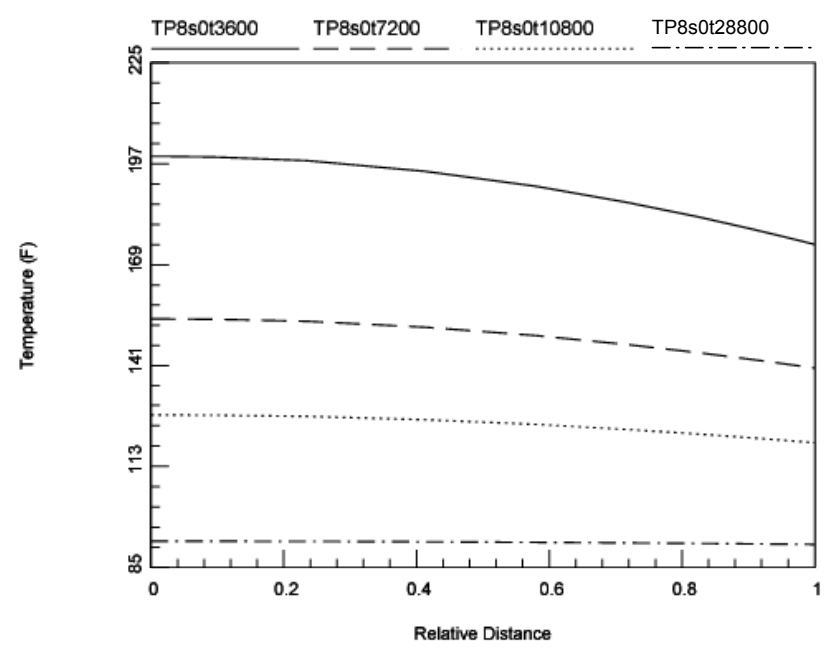

Figure 19. Temperature of outer block at lower level for Case 3.

The temperature at 8 hours of cooling is about $90^{\circ} \mathrm{F}$ for the blocks on the outer portion of the racks. This shows that a large amount of cooling is achieved by just circulating atmospheric air through the cooling room.

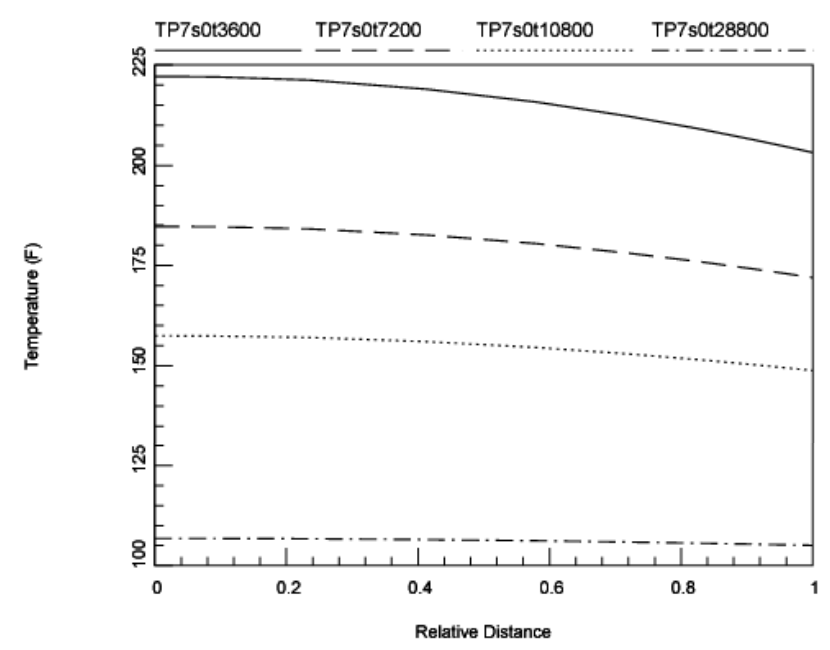

Figure 20. Temperature inner block at lower level for Case 3. 
After 8 hours of cooling the inner blocks are still slightly above $100^{\circ} \mathrm{F}$. This case yields higher temperatures for the blocks but still does not pose any threat to the quality of the product.

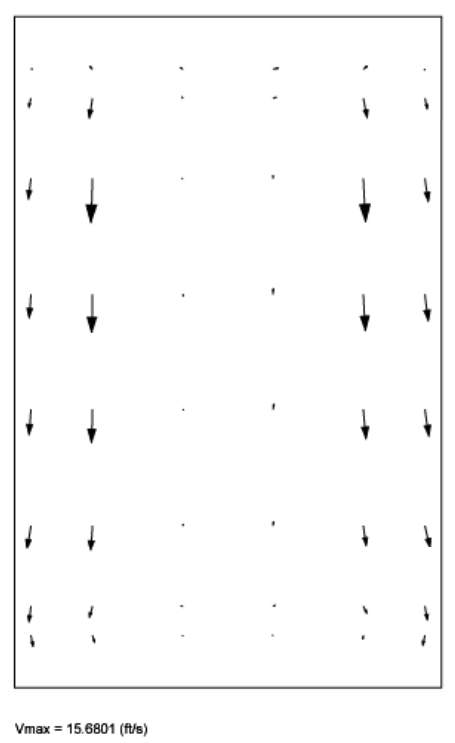

Figure 21. Air velocities at lower level for Case 3.

The velocity vector plot above shows the cause of the temperature difference between the inner and outer blocks. The blocks on the outer edge get more of the circulated air, thus causing them to cool at a higher rate. Once the heat is transferred to the air from the blocks the fans, the fans carry the hot air away. However, at the inner blocks the air is not moving as fast and the heat transfer is slowed. 


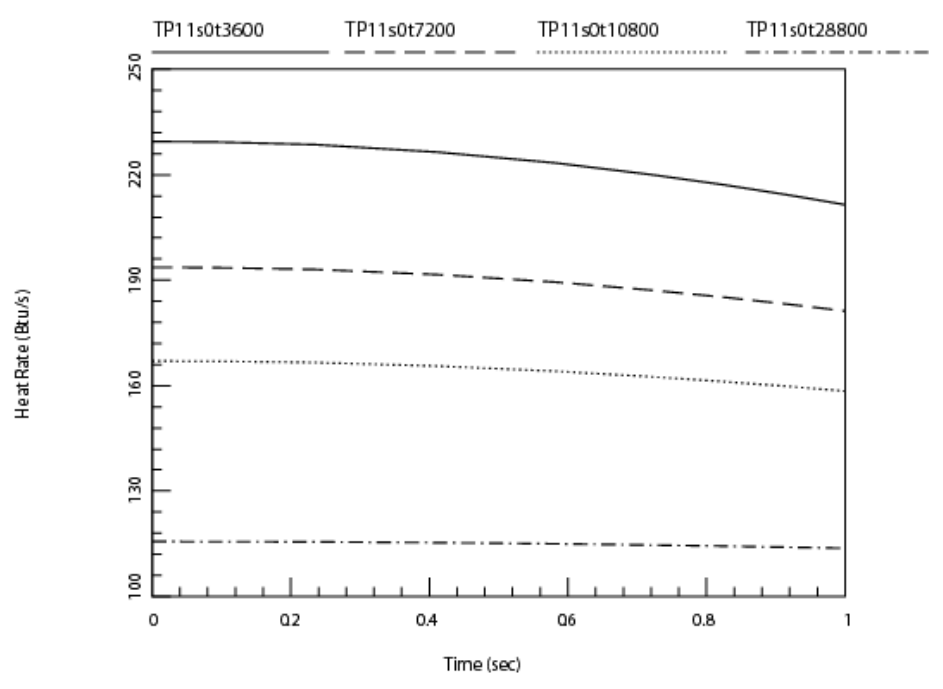

Figure 22. Temperature inner block at mid level for Case 3.

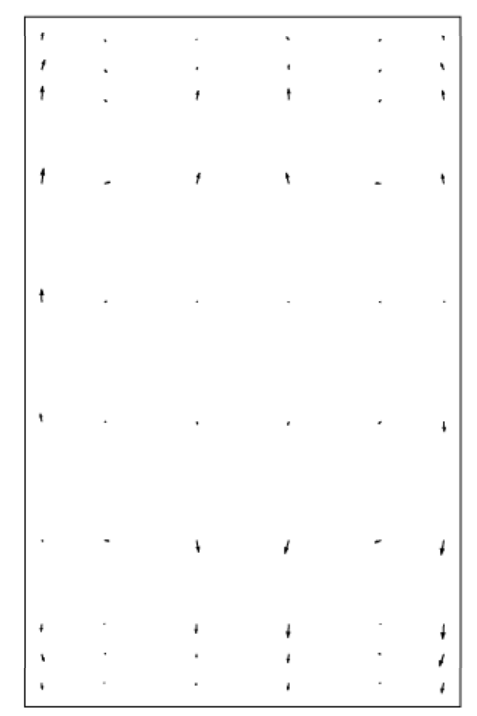

$V \max =4.51627$ (ttrs)

Figure 22. Air velocities at mid level for Case 3.

The blocks at the mid level of the room again are cooled at a slower rate than those in the lower level of the arrangement. For this case the temperature for the inner blocks at mid level are at $113^{\circ} \mathrm{F}$. The plot above shows that the airflow is at mid level of the cooling 
racks the airflow seems to be more uniform throughout but very small in magnitude. The lower and upper levels have higher airflow rates but airflow is not uniform. This causes the inner and outer blocks to cool at different rates.

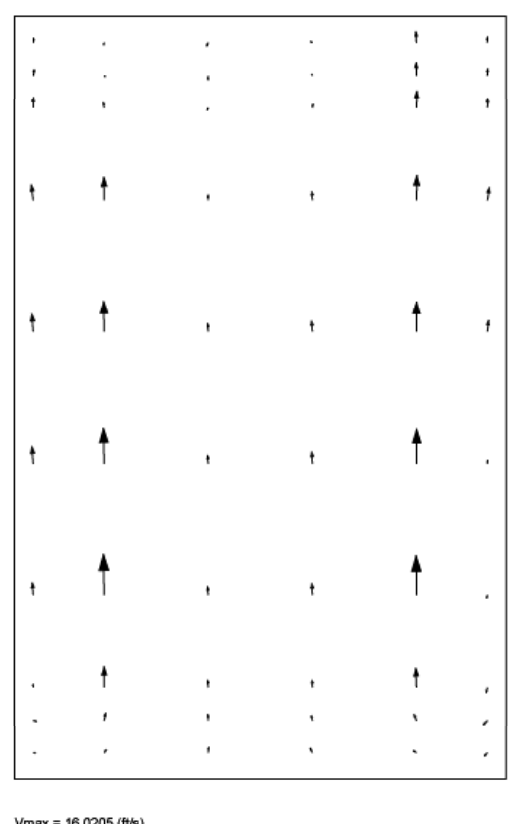

Figure 23. Air velocities at upper level for Case 3.

\section{Case 4}

The objective of this case is to determine whether curtains can be effectively installed in empty racks to force the air in the direction of the racks that contained blocks. During most day-to-day operations at the facility the cooling racks are rarely full. The current setup allows air to flow along the path of empty racks. By simulating curtains that would restrict the flow of air to only racks that contain foam, results could determine if this would be a more efficient process. In GOTHIC area porosity is used to control the 
amount of area on a face in the control subvolume. To simulate a curtain the area porosity is set to zero in the flow direction of the cells that don't contain foam blocks. The blocks for this simulation are located at the lower (level 1), mid (level 4) and top (level 6) all other racks are empty. Curtains were placed at the ends of the racks that did not contain blocks.

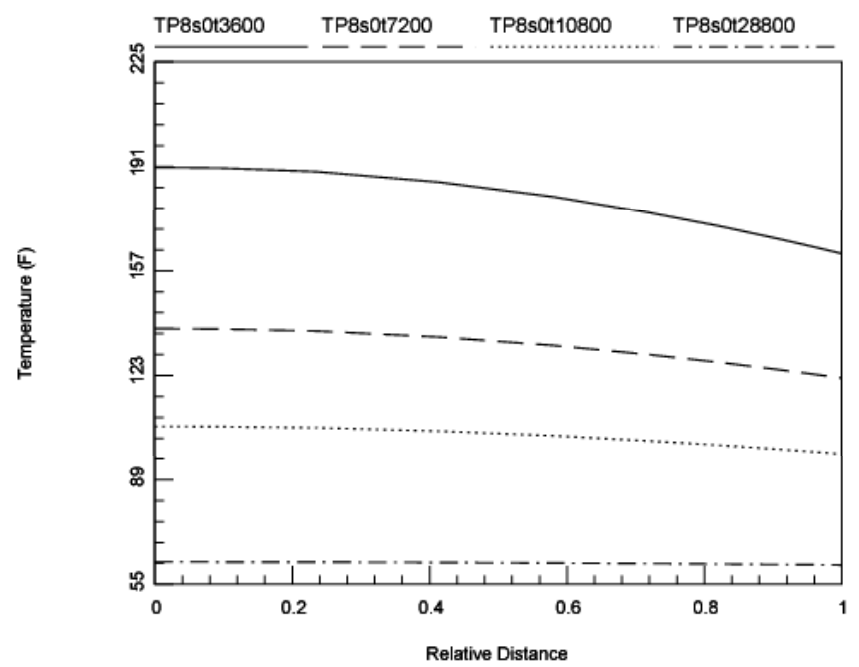

Figure 24. Temperature of outer block at lower level for Case 4.

The results at 8 hours show that the outer blocks cool to nearly the same temperature as Case 1. At earlier times during cooling the outer blocks are not cooling as fast as Case 1. 


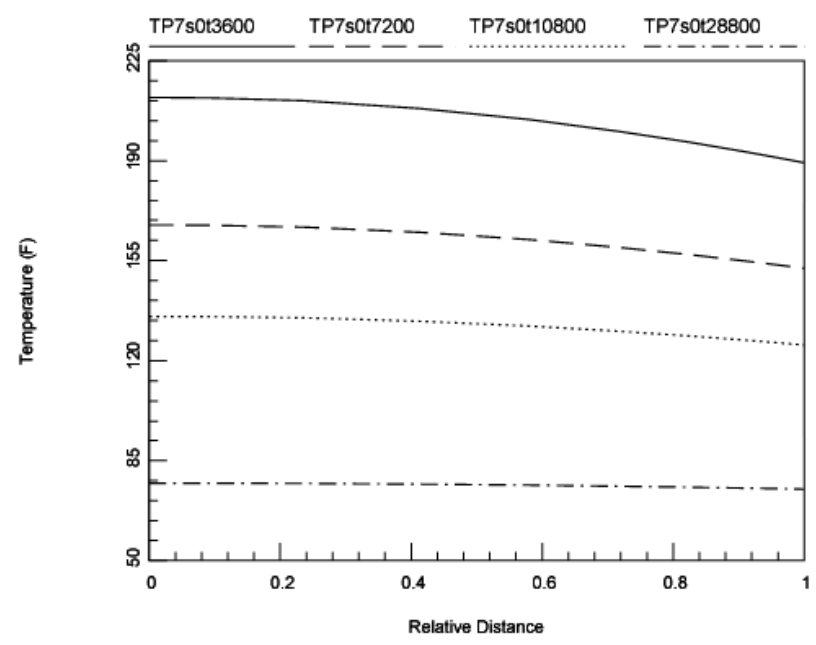

Figure 25. Temperature of inner block at lower level for Case 4.

This profile shows that the effort to force the flow in the direction of the racks that contain blocks doesn't help much in the cooling process. The inner blocks cool at a slower rate than the outer blocks.

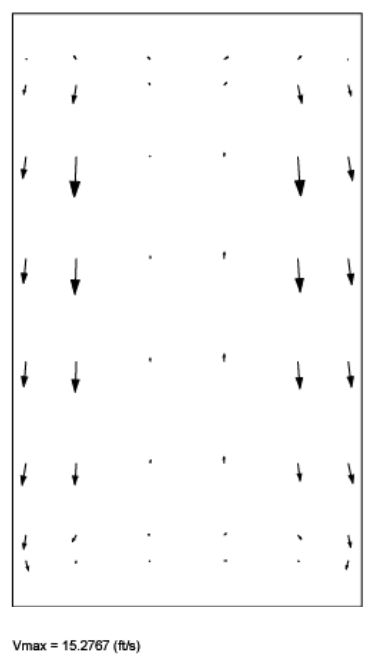

Figure 26. Air velocities at lower level for Case 4. 
The vector plot details the flow during the process. Although curtains are placed on racks that contain no blocks the flow continues around the edge of the racks. There is very little flow in the center of the racks. The HVAC ducts are located around the perimeter of the room. With the ducts in this location it is not feasible to place curtains to prevent flow around the edge.

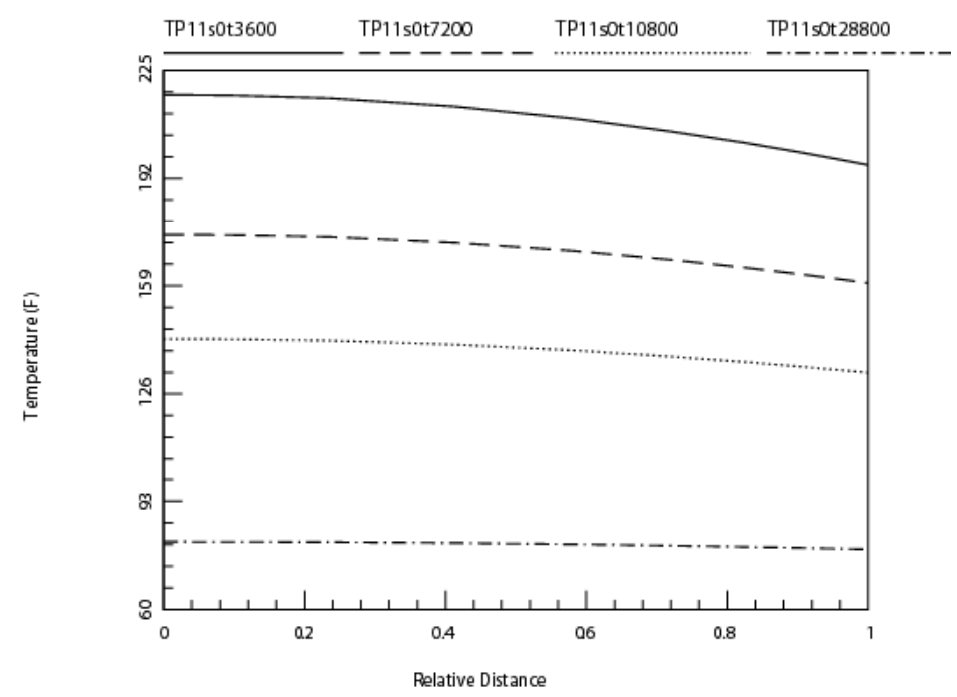

Figure 27. Temperature of inner block at mid level for Case 4. 


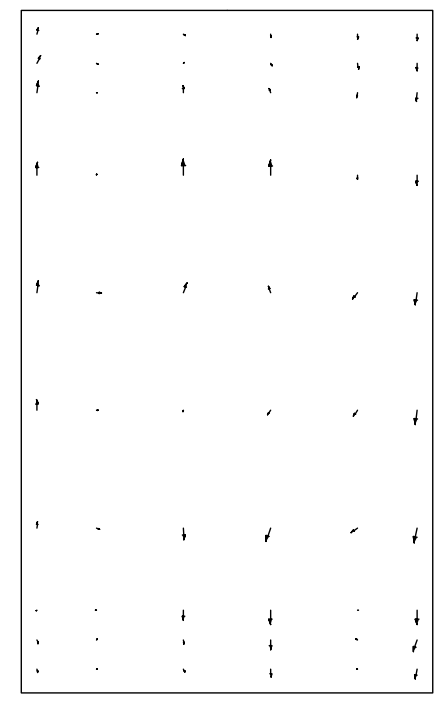

$V_{\max }=5.29277(\mathrm{ft} / \mathrm{s})$

Figure 28. Air velocities in mid level of room.

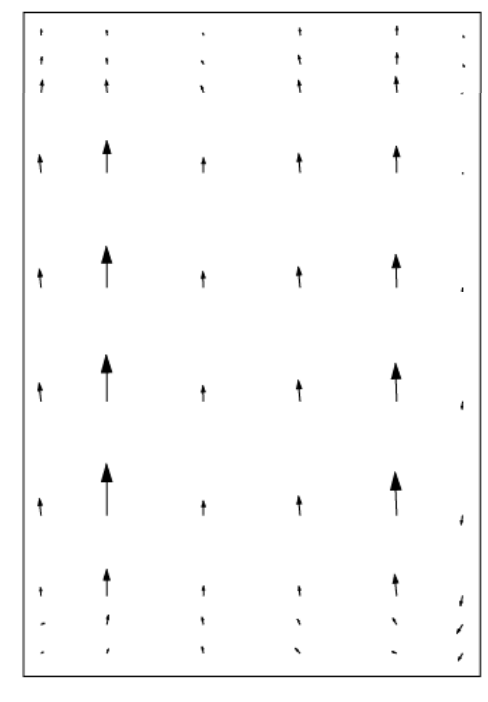

$V_{\max }=16.7844(\mathrm{ft} / \mathrm{s})$

Figure 29. Air velocities in upper level of room.

With the curtain installed the mid level velocities are low like in the pervious cases.

However, the mid level velocities are not very uniform, which is a disadvantage in the 
cooling process. The ideal situation is to have uniform cooling such that all blocks require the same amount of time to cool.

\section{Case 5}

The results from Case 1 showed that the existing circulation fans are not effective in moving air through the center section of the cooling room. Case 5 models the cooling room with 4 additional fans installed. The four additional fans are attached to the ceiling and floor. By adding circulation fans the goal is to achieve a faster cooling rate for the blocks. This would eliminate the need to use the HVAC for an extended period of time.

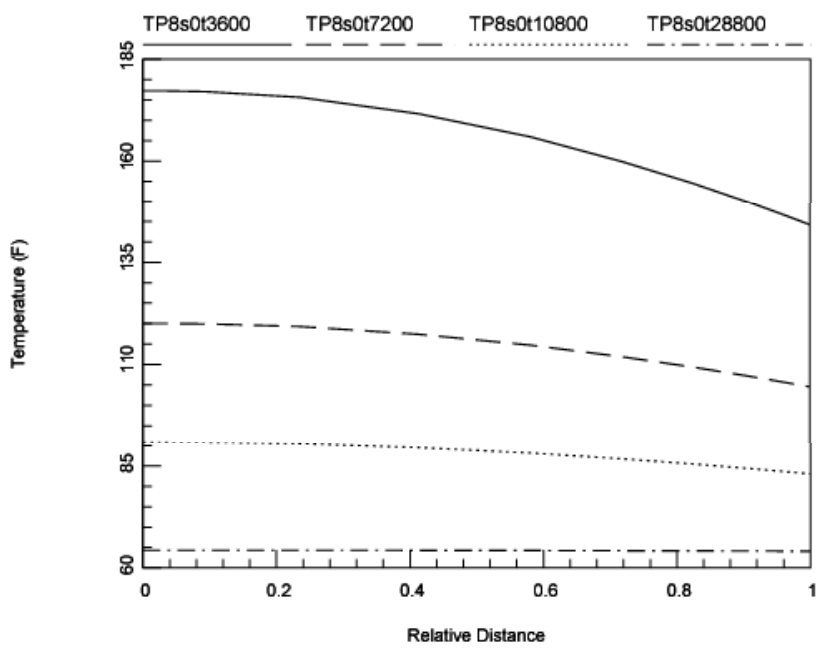

Figure 30. Temperature of outer block at lower level for Case 5.

When compared to case 1 the temperature of the outer block is $11^{\circ} \mathrm{F}$ cooler at 1 hour. This trend continues for until the entire block is $60^{\circ} \mathrm{F}$ at 8 hours of cooling. 


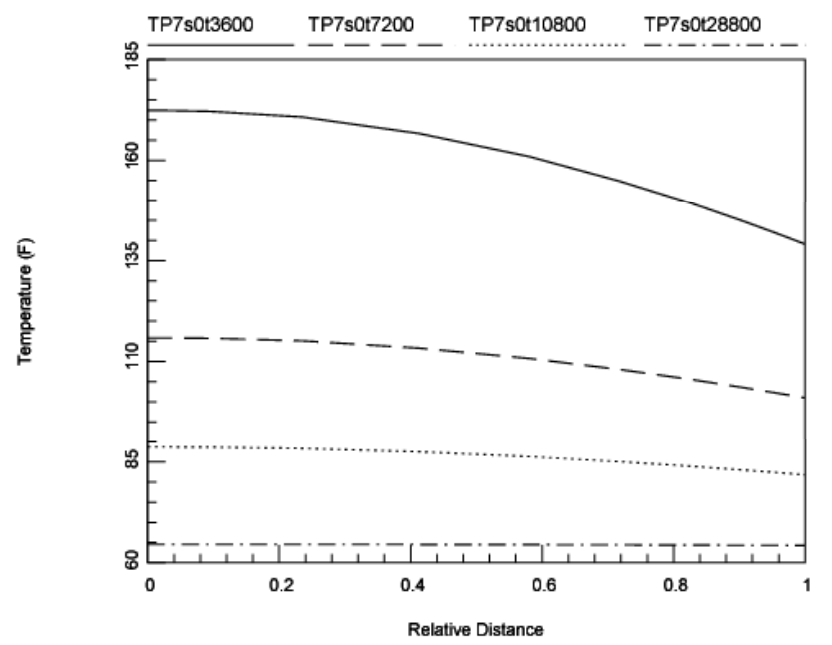

Figure 31. Temperature of inner block at lower level for Case 4.

The cooling of the inner blocks for case 5 is more efficient than case 1 . At 1 hour of cooling time the inner block for case 5 is $30^{\circ} \mathrm{F}$ cooler than the same block in case 1 . Now that 4 addition fans have been added to the process the inner and outer blocks are cooling at the same rate.

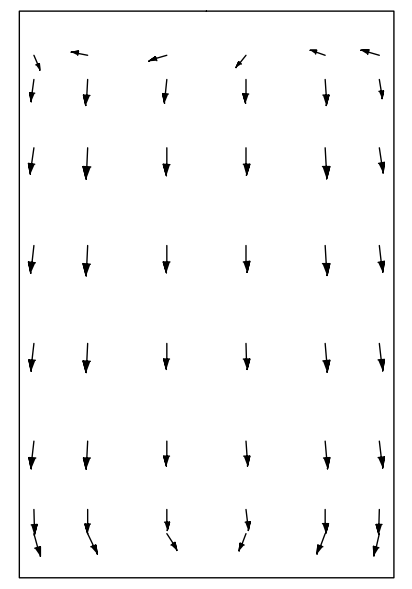

$V_{\max }=17.0858(\mathrm{ft} / \mathrm{s})$

Figure 32. Air velocities at lower level Case 5. 


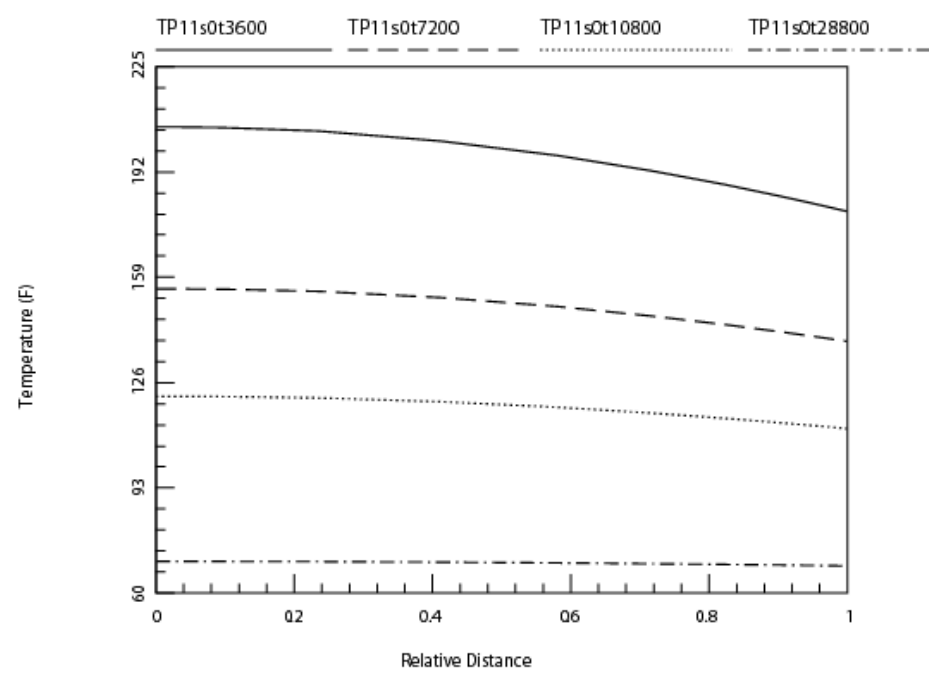

Figure 33. Temperature of inner block at mid level for Case 5.

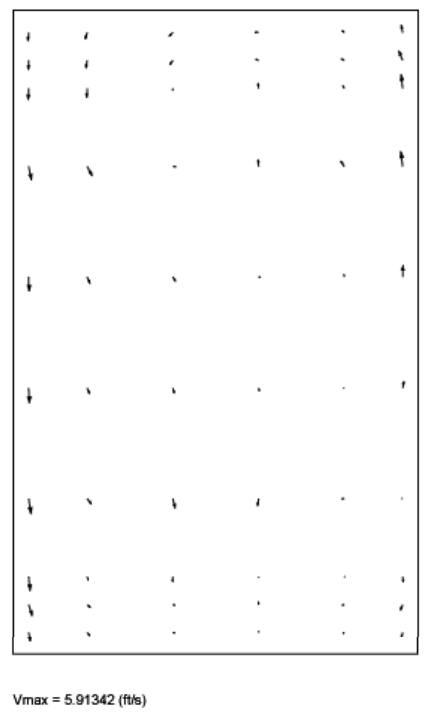

Figure 34. Air velocities in mid level Case 5. 


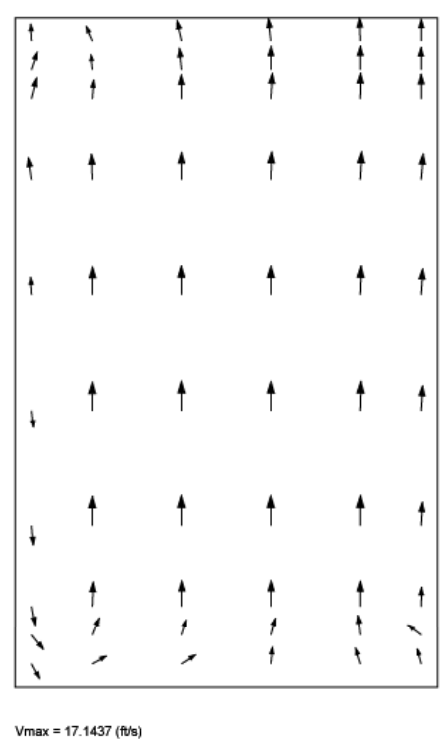

Figure 35. Air velocities at upper level Case 5.

The velocity plots show the uniform velocity profile in the room. This uniform profile allows for uniform cooling of the blocks. As evident in figures 29 and 31 the upper an lower velocity profiles are large and uniform. The mid level velocity has a uniform profile but has a smaller rate. Again this is caused by the circulation fans being attached to the floor and ceiling. The added fans allow for faster cooling and the uniform velocity profile allows all blocks to cool at same rate. The faster cooling rate allows for a reduction in the use of the HVAC system.

\section{Case 6}

The results from Case 5 showed that the additional circulation fans drastically improved the airflow pattern and the overall cooling rates. Case 6 investigates the feasibility of turning of the refrigeration system and operating with ambient air and circulation fans 
only. In this case, ambient air at $85^{\circ} \mathrm{F}$ would enter the room in place of conditioned air at $55^{\circ} \mathrm{F}$.

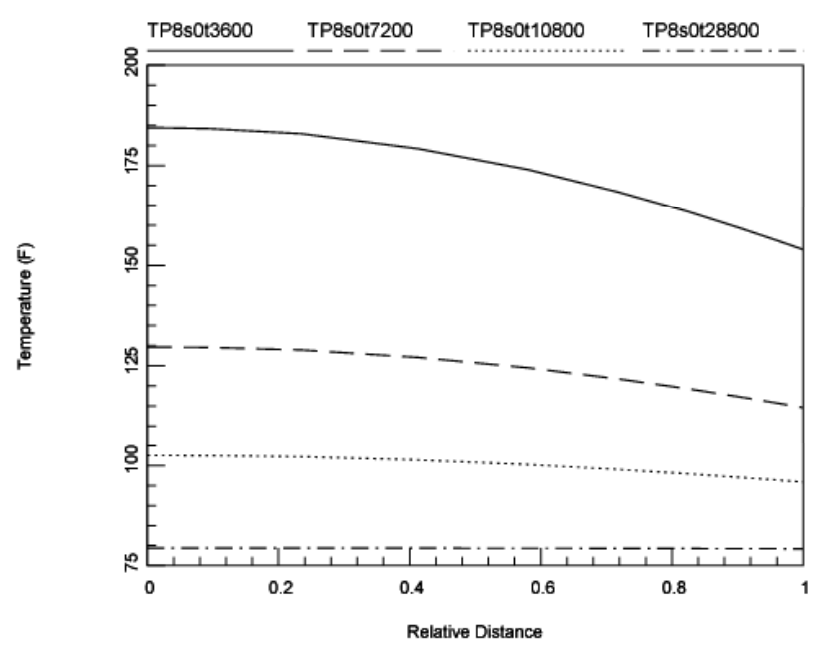

Figure 36. Temperature of outer block at lower level Case 6.

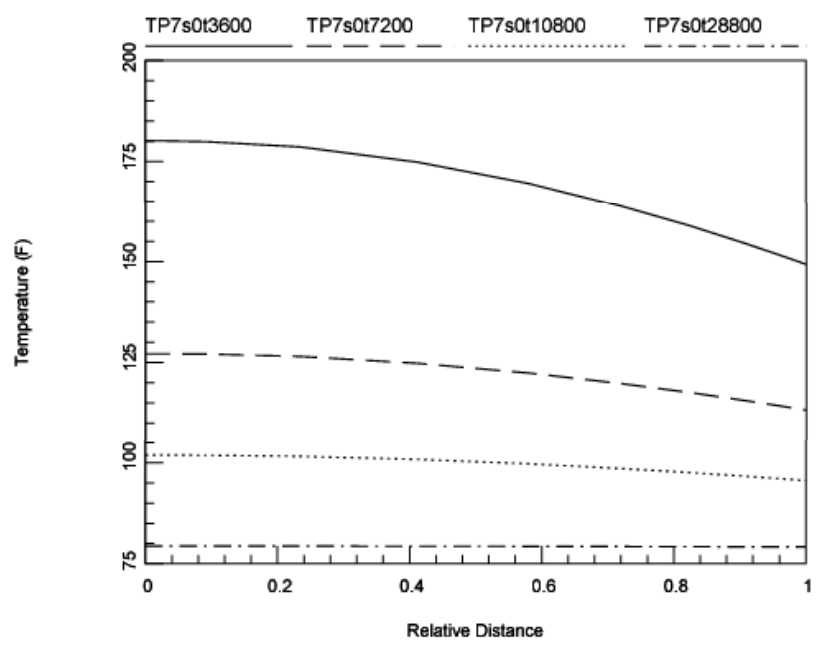

Figure 37. Temperature of inner block at lower level Case 6.

Graphs 22 and 23 show that the blocks in this case are able to achieve more cooling than those in case 3. Neither case uses the HVAC system. However, in the present case the 
four additional fans are utilized. This creates a uniform flow in the cooling room and the temperature after 8 hours is lower.

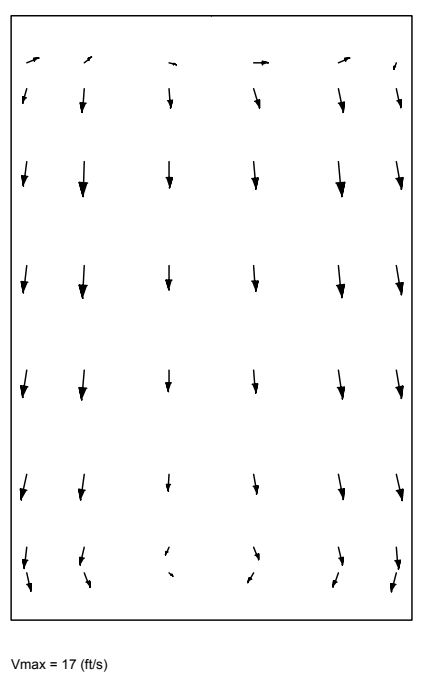

Figure 38. Air velocities at lower level Case 6.

The plot above confirms that the velocity pattern in the room is uniform with the addition of 4 fans. The addition of the 4 fans also increases the velocity thus decreasing the cooling time by about 4 hours. Even with the HVAC not being used better cooling results are achieved. 


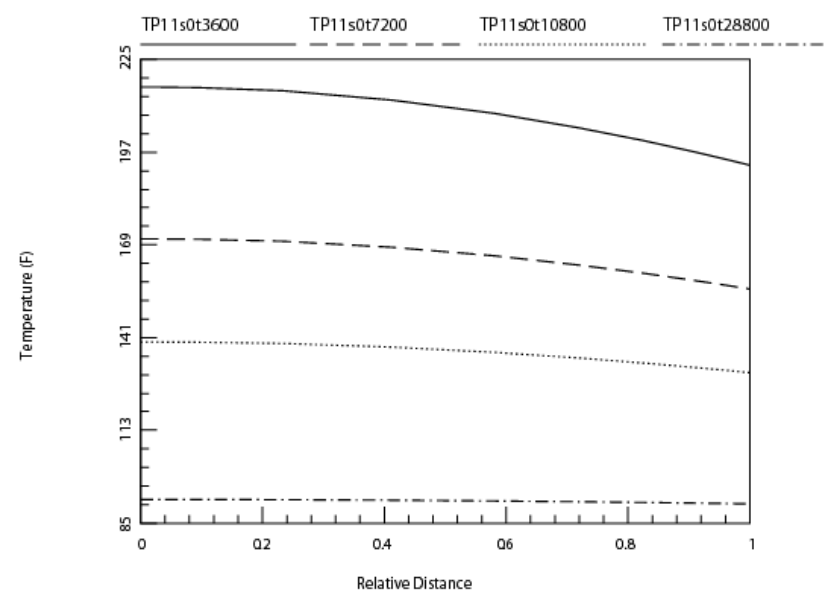

Figure 39. Temperature of inner block at mid level Case 6.

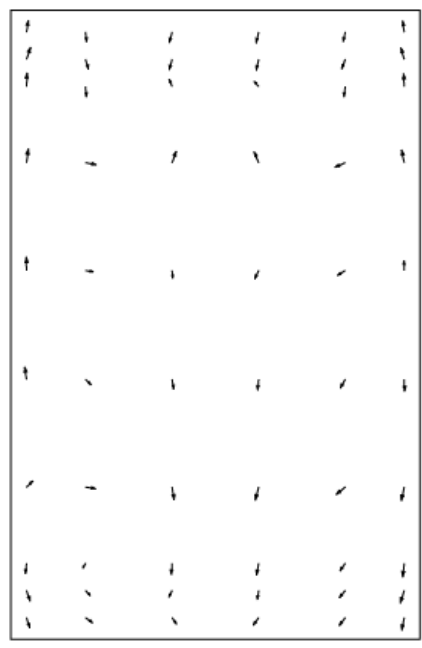

$\mathrm{V} \max =5.25217(\mathrm{ft} / \mathrm{s})$

Figure 40. Air velocities at mid level Case 6. 


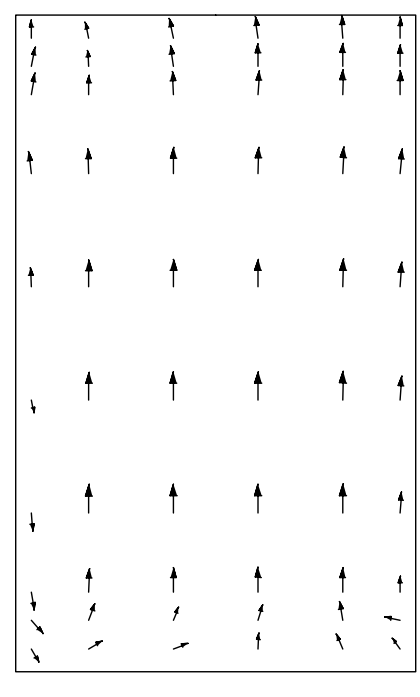

$V \max =16.9675(\mathrm{ft} / \mathrm{s})$

Figure 41. Air velocities at upper level Case 6.

The plots above show the airflow velocities are all uniform but the mid level velocity is lower than the lower and upper levels but the velocities are uniform. The middle blocks take longer to cool than the blocks in the lower and upper portion of the cooling racks.

\section{Case 7}

Each previous case had low air velocities at the mid level. This causes the blocks at the mid level to cool slightly slower than the blocks located at the lower and upper levels. Case 7 simulates adding fans at the mid level to increase the air velocity. The increased velocity should increase the cooling rate of the blocks located at the mid level. The objective is to create more circulation at the mid level to enhance the cooing of theses blocks. 


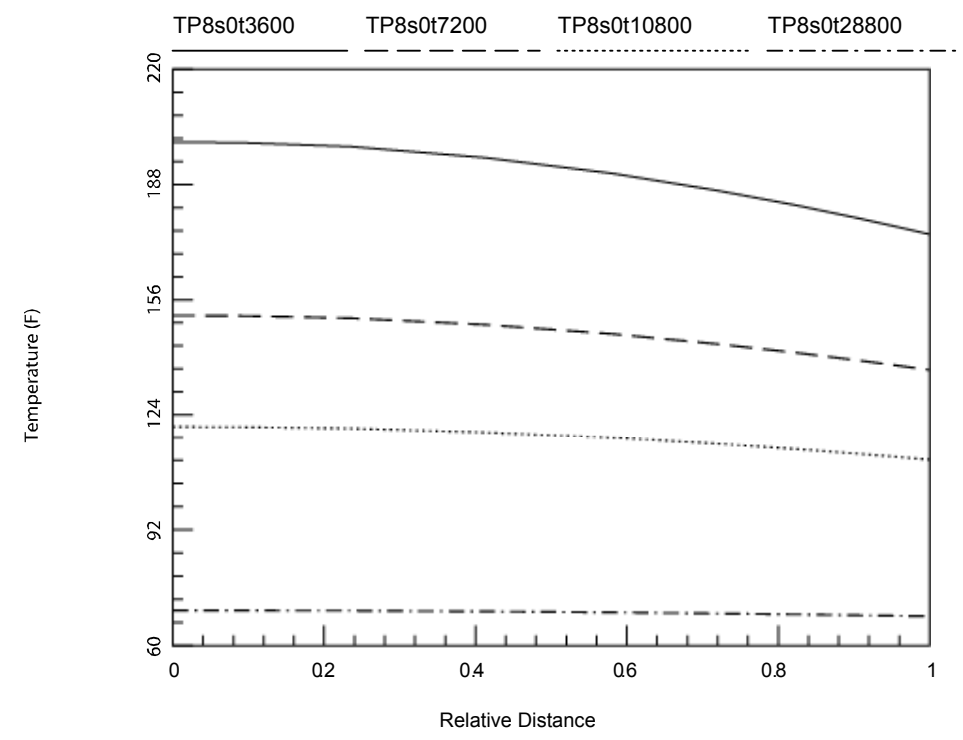

Figure 42. Temperature of outer block at lower level Case 7.

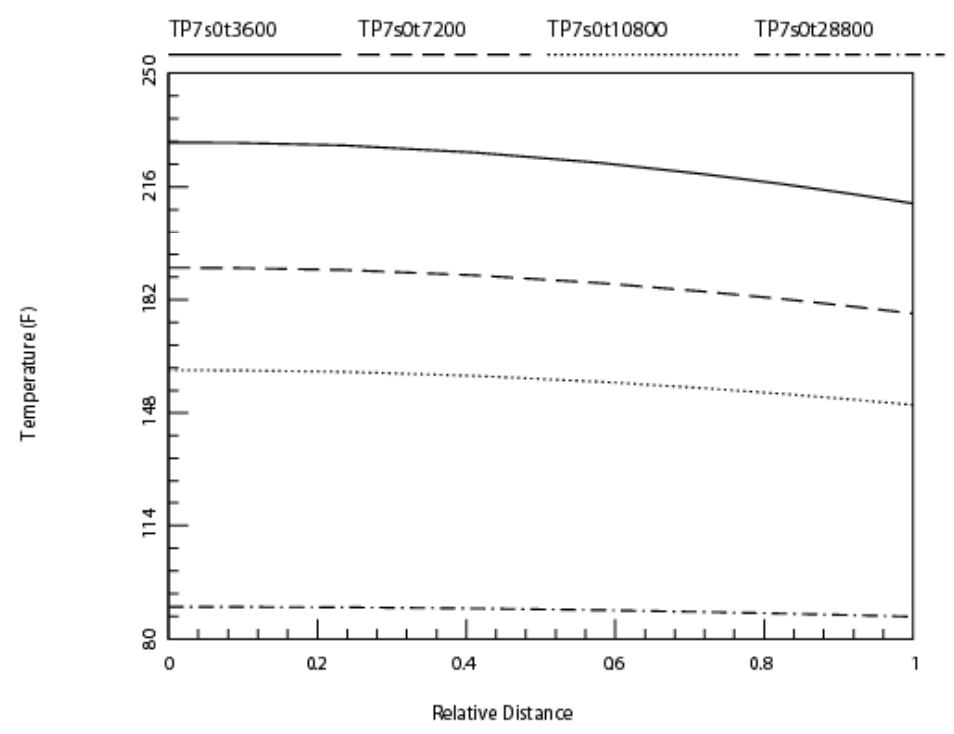

Figure 43. Temperature of inner block at lower level Case 7.

Adding fans at the mid level did not make the temperature of the inner and outer blocks on the lower level uniform. The outer blocks are cooling at a faster rate than the inner blocks. 


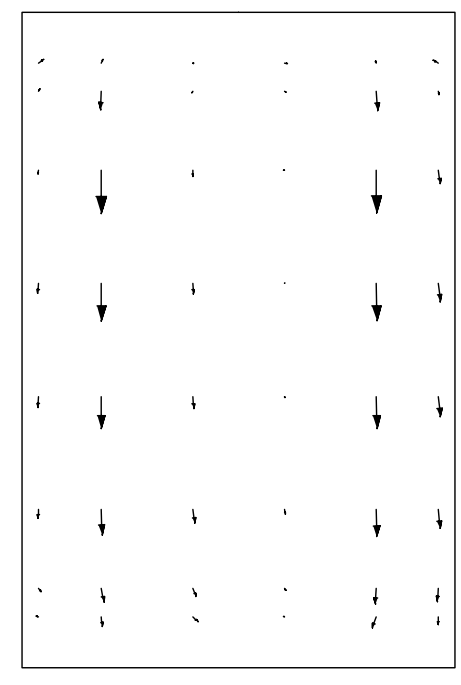

$V \max =16.0029(\mathrm{t} / \mathrm{s})$

Figure 44. Air velocities at lower level Case 7.

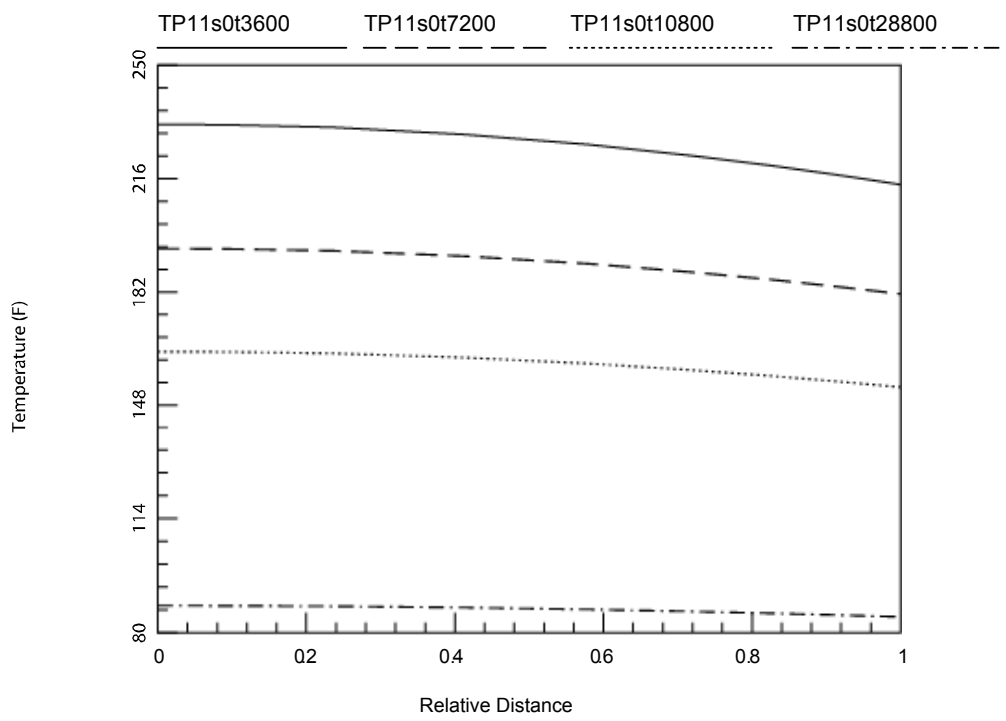

Figure 45. Temperature of inner block at mid level Case 7.

The inner blocks at mid level are cooling at or near the same rate as the inner blocks at lower level. 


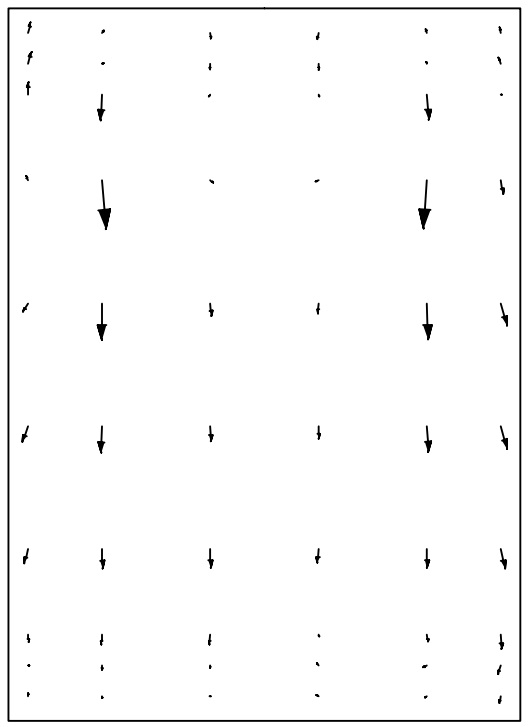

$\mathrm{Vmax}=14.9328(\mathrm{ft} / \mathrm{s})$

Figure 46. Air velocities at mid level Case 7.

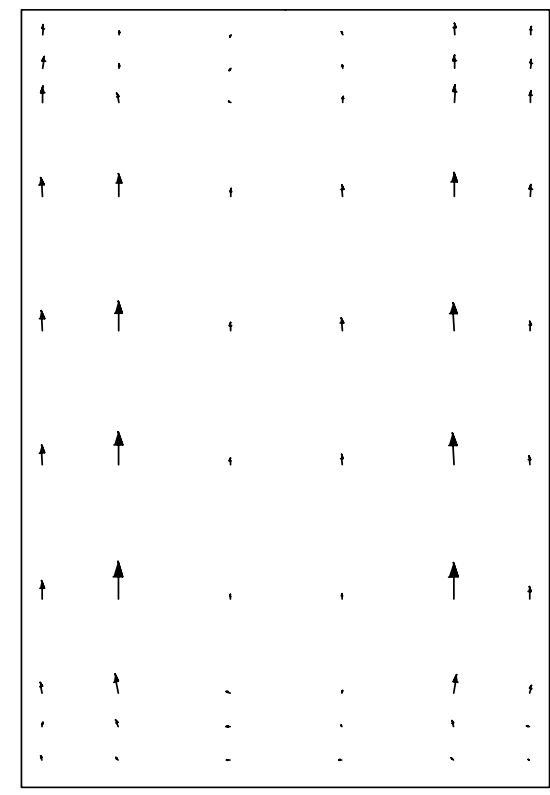

$V \max =15.9232(\mathrm{ft} / \mathrm{s})$

Figure 47. Air velocities at upper level Case 7. 
The velocities at mid level for case 7 are similar to those velocities at the lower and upper levels. The additional fans cause the blocks to cool at similar rates. The blocks on the outer part of the rack are still cooled faster than those at the inner part of the rack. 


\section{Recommendations}

All case results were studied to find advantages that may benefit the facility in efforts to reduce energy usage. For the case 2 where the circulation fans are not in operation, an electrical costs saving could be realized. The electrical power required to operate each fan is give by:

$$
\begin{gathered}
\text { Power }=\frac{\left(\text { Motor HP } \times .746 \frac{\mathrm{kW}}{\mathrm{HP}}\right)}{\text { efficiency }} \\
\text { Power }=\frac{\left(15 \mathrm{HP} \times .746 \frac{\mathrm{kW}}{\mathrm{HP}}\right)}{.9} \\
\text { Power }=12.43 \mathrm{~kW}
\end{gathered}
$$

The electrical energy savings that would result if one fan were to be deactivated is

$$
\begin{gathered}
\text { Energy }=12.43 \mathrm{~kW} \times 5000 \mathrm{hrs} \\
\text { Energy }=62,150 \frac{\mathrm{kW} \cdot \mathrm{h}}{\mathrm{yr}}
\end{gathered}
$$

The annual electrical cost savings is:

$$
\begin{gathered}
\text { Electrical Cost }=62,150 \frac{\mathrm{kW} \cdot \mathrm{h}}{\mathrm{yr}} \times \frac{\$ .027}{\mathrm{~kW} \cdot \mathrm{h}}+12.43 \mathrm{~kW} \times \$ \frac{9.42}{\mathrm{~kW}} \times 12 \text { months } \\
\text { Electrical Cost }=\$ 3083 \text { per year per fan }
\end{gathered}
$$

The annual cost to operate four fans is

$$
\text { Cost of } 4 \text { fans }=\$ 12,332 \text { per year }
$$


The operational cost of the HVAC system was also calculated. The analysis was based on a 175-ton chiller and air handling system.

$$
\text { Power }=\frac{\left(\text { Motor HP } \times .746 \frac{\mathrm{kW}}{\mathrm{HP}}\right)}{\text { efficiency }}
$$

The compressor, pump, and fan motor power for a chiller this size is about 1HP per ton. Therefore, the electrical power required to operate the HVAC system is

$$
\begin{gathered}
\text { Power }=\frac{\left(175 \mathrm{HP} \times .746 \frac{\mathrm{kW}}{\mathrm{HP}}\right)}{.9} \\
\text { Power }=145.05 \mathrm{~kW} \\
\text { Energy }=145.05 \mathrm{~kW} \times 5000 \mathrm{hrs} \\
\text { Energy }=725,250 \frac{\mathrm{kW} \cdot \mathrm{h}}{\mathrm{yr}} \\
\text { Cost }=725,250 \frac{\mathrm{kW} \cdot \mathrm{h}}{y r} \times \frac{\$ .027}{\mathrm{~kW} \cdot \mathrm{h}}+145.05 \mathrm{~kW} \times \$ \frac{9.42}{\mathrm{~kW}} \times 12 \text { months } \\
\text { Cost }=\$ 35,978 \text { per year }
\end{gathered}
$$

The time required for cooling the blocks determines the amount of energy needed to complete the cooling process. The energy savings is based on the energy usage of the equipment used in the cooling process. Modifications are added as a variable to help the facility determine the downtime and/or man-hours needed to change the setup. No information was provided for man-hour rates of downtime cost therefore no estimate was give for making any modifications.

The energy conservation opportunities presented in this study are summarized in Table 2 . 
Several cost saving opportunities are compared to the present plant setup. Three of the cases investigated in this work would conserve energy. Case 2, which would disable the circulation fans, would save about $\$ 12,300 /$ year but would increase the cooling time required by about $3 \%$. Case 3 which would retain the circulation fans but disable the chiller would save $\$ 36,000$ in electrical costs but would increase the cooling time required by about $5 \%$. Product quality tests at the facility will be needed to determine whether this option is acceptable. Case 6 , which would add new circulation fans and disable the chiller, would save about $\$ 23,700 /$ year in electrical costs and would reduce the cooling time by about $33 \%$. It would also eliminate the annual maintenance costs for the chiller. The blocks should be placed in the lower and upper racks around the edges first.

\begin{tabular}{|c|c|c|c|c|}
\hline Case \# & Description & $\begin{array}{c}\text { Estimated } \\
\text { Energy Cost } \\
\text { Savings }\end{array}$ & $\begin{array}{c}\text { Time required } \\
\text { to cool blocks } \\
\text { to } 95^{\circ} \mathrm{F}\end{array}$ & $\begin{array}{c}\text { Modifications } \\
\text { Required }\end{array}$ \\
\hline 1 & $\begin{array}{c}\text { Current plant } \\
\text { setup }\end{array}$ & ----- & $5.41 \mathrm{hrs}$ & None \\
\hline 2 & $\begin{array}{c}\text { Circulation } \\
\text { Fans Off }\end{array}$ & $\$ 12,300 /$ year & $5.58 \mathrm{hrs}$ & None \\
\hline 3 & $\begin{array}{c}\text { HVAC Off- } \\
\text { Circulation } \\
\text { Fans On }\end{array}$ & $\$ 50,724 /$ year & $8.10 \mathrm{hrs}$. & None \\
\hline 4 & $\begin{array}{c}\text { Curtains } \\
\text { Installed on } \\
\text { Empty Racks }\end{array}$ & ---- & $5.41 \mathrm{hrs}$. & $\begin{array}{c}\text { Add plastic } \\
\text { curtains to end } \\
\text { of racks }\end{array}$ \\
\hline 5 & $\begin{array}{c}\text { Adding Fans } \\
\text { with HVAC on }\end{array}$ & ----- & $2.70 \mathrm{hrs}$. & $\begin{array}{c}\text { Install 4 new } \\
\text { fans }\end{array}$ \\
\hline 6 & $\begin{array}{c}\text { Adding Fans } \\
\text { with HVAC off }\end{array}$ & $\$ 23,646 /$ year & $3.61 \mathrm{hrs}$. & $\begin{array}{c}\text { Install 4 new } \\
\text { fans }\end{array}$ \\
\hline
\end{tabular}

Table 2 - Results of cases modeled 


\section{Conclusions}

A GOTHIC model of an industrial HVAC cooling process was constructed to predict the effects of proposed process modifications. Comparisons of predicted performance and experimental data were used to validate the computer model. This study showed that GOHTIC could very effectively be used to predict effects of process modifications. This study also showed that the time involved in creating models is fairly short. With help from the staff, a new engineering student in the Industrial Assessment Center can learn to create a GOTHIC model in a few weeks. The time required for a veteran student to construct a model is a few days. Once the model is set up modifications can be made within minutes. The model usually takes a few hours to run on a personal computer. The software makes it possible to model processes and to evaluate energy conservation measures that otherwise would be too complicated to consider. It greatly extends the capabilities of the IAC, and will help the IAC staff to recommend new well-documented measures to conserve energy. It should help to improve the implementation rate of IAC recommendations. 


\section{References}

1. George T.L., et al. GOTHIC CONTAINMENT ANALYSIS PACKAGE USER MANUAL. Version 7.1, Numerical Applications Inc. Richland, Washington. September 2002.

2. Incropera, F.P. and Dewitt D.P. (1996). Introduction to Heat Transfer. $3^{\text {rd }}$ ed. New York: John Wiley \& Sons.

3. Leach J.W., et al. Energy Conservation Report (NC-0253). North Carolina State University Industrial Assessment Center. Raleigh, NC. 2003. 